This item was submitted to Loughborough's Research Repository by the author.

Items in Figshare are protected by copyright, with all rights reserved, unless otherwise indicated.

\title{
Influence of purge flow swirl at exit to the high-pressure compressor on OGV/pre-diffuser and combustion system aerodynamics
}

\section{PLEASE CITE THE PUBLISHED VERSION}

https://doi.org/10.1115/1.4043781

\section{PUBLISHER}

(c) American Society of Mechanical Engineers (ASME)

\section{VERSION}

AM (Accepted Manuscript)

\section{PUBLISHER STATEMENT}

This paper was accepted for publication in the journal Journal of Turbomachinery and the definitive published version is available at https://doi.org/10.1115/1.4043781.

\section{LICENCE}

CC BY 4.0

\section{REPOSITORY RECORD}

Walker, Duncan, Bharat R. Koli, and Peter Beecroft. 2019. "Influence of Purge Flow Swirl at Exit to the Highpressure Compressor on Ogv/pre-diffuser and Combustion System Aerodynamics". Loughborough University. https://hdl.handle.net/2134/37748. 


\section{American Society of Mechanical Engineers}

SETTING THE STANDARD

ASME Accepted Manuscript Repository

Institutional Repository Cover Sheet

First
\[ \begin{array}{c}\text { Last } \\ \text { Influence of Purge Flow Swirl at Exit to the High-Pressure Compressor on OGV/Pre-Diffuser and }\end{array} \]
ASME Paper Title: Combustion System Aerodynamics

Authors: $\quad$ A. Duncan Walker, Bharat Koli, Peter A. Beecroft

ASME Journal Title: Journal of Turbomachinery

Date of Publication (VOR* Online) June 14,

Volume/Issue $141(9)$ 2019

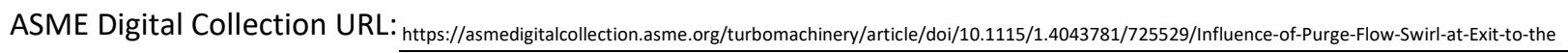

DOI: $\quad$ https://doi.org/10.1115/1.4043781

*VOR (version of record) 


\title{
Influence of Purge Flow Swirl at Exit to the High- Pressure Compressor on OGV/Pre-Diffuser and Combustion System Aerodynamics
}

\author{
Walker, A Duncan* \\ Senior Lecturer, Loughborough University \\ Department of Aeronautical and Automotive Engineering, \\ Loughborough University, Loughborough, Leicestershire, LE11 3TU, UK. \\ A.D.Walker@lboro.ac.uk \\ Koli, Bharat \\ Research Associate, Loughborough University \\ Department of Aeronautical and Automotive Engineering, \\ Loughborough University, Loughborough, Leicestershire, LE11 3TU, UK. \\ B.Koli@lboro.ac.uk

\section{Beecroft, Peter A} \\ Rolls-Royce plc \\ SIN-A-65, Rolls-Royce plc, PO Box 31, Moor Lane, Derby, DE24 8BJ, UK \\ Peter.Beecroft@Rolls-Royce.com \\ *corresponding author
}

\footnotetext{
ABSTRACT

As aero gas turbine designs strive for ever greater efficiencies the trend is for engine overall pressure ratios to rise. Although this provides greater thermal efficiency it means that cycle temperatures also increase. One potential solution to managing the increasing temperatures is to employ a cooled cooling air system. In such a system a purge flow into the main gas path downstream of the compressor will be required to prevent hot gas being ingested into rotor drive cone cavity. However, the main gas path in compressors is aerodynamically sensitive and it is important to understand, and mitigate, the impact such a flow may have on the compressor outlet guide vanes, pre-diffuser and the downstream combustion system
} 
Influence of Purge Flow Swirl at Exit to the High-Pressure Compressor on OGV/Pre-Diffuser and Combustion System Aerodynamics

aerodynamics. Initial CFD predictions demonstrated the potential of the purge flow to negatively affect the outlet guide vanes and alter the inlet conditions to the combustion system. The purge flow modified the incidence onto the outlet guide vane, at the hub, such that the secondary flows increased in magnitude. An experimental assessment carried out using an existing fully annular, isothermal test facility confirmed the CFD results and importantly demonstrated that the degradation in the combustor inlet flow resulted in an increased combustion system loss. At the proposed purge flow rate, equal to $1 \%$ of the mainstream flow, these effects were small with the system loss increasing by $\sim 4 \%$. However, at higher purge flow rates (up to 3\%) these effects became notable and the outlet guide vane and pre-diffuser flow degraded significantly with a resultant increase in the combustion system loss of $\sim 13 \%$. To mitigate these effects CFD was used to examine the effect of varying the purge flow swirl fraction in order to better align the flow at the hub of the outlet guide vane. With a swirl fraction of 0.65 ( $x$ rotor speed) the secondary flows were reduced below that of the datum case (with no purge flow). Experimental data showed good agreement with the predicted flow topology and performance trends but the measured data showed smaller absolute changes. Differences in system loss were measured with savings of around $10 \%$ at the turbine feed ports for a mass flow ratio of $1 \%$ and a swirl fraction of 0.65 .

Keywords: gas turbine combustion system aerodynamics, OGV, pre-diffuser, swirl, rim purge flow, turbine cooling. 


\section{INTRODUCTION}

With the projected growth of air traffic, it is essential that new technologies are introduced that will mitigate the negative impact this will have on the environment. For example, ACARE's "Flightpath 2050" [1] document outlines stringent guidelines for the future emission of pollutants such as $\mathrm{CO}_{2}, \mathrm{CO}, \mathrm{NO}_{x}$, unburnt hydrocarbons, soot particulates and smoke. As aero gas turbine designers strive for ever greater efficiencies and reduced fuel burn the trend has been for engine overall pressure ratios (OPR) to rise. Higher OPR allows greater thermal efficiencies and provides higher thrust for a given core size. However, this also means that cycle temperatures increase which has resulted in a great deal of development in cooling technologies in order to enable the turbine to operate at excessively high temperatures. In modern gas turbines compressor exit air is routinely used to cool components in the combustion and turbine systems but as OPR rises the compressor exit temperature will also increase making its use for cooling less efficient. Without the development of new technologies this will affect the operation life of critical parts within the turbine or require unacceptably high cooling flows, which will negate the goal of a reduction in specific fuel consumption. A potential solution to this issue is so-called cooled cooling air (CCA). As discussed by Walker at al. [2], in a CCA system, some of the compressor efflux is diverted for additional cooling in a heat exchanger $(\mathrm{HX})$ cooled by air from the engine's bypass duct before the cooled air is then ducted for use in component cooling (see Fig. 1).

In a traditionally cooled architecture an amount of compressor exit air is usually bled from the main gas path into the rotor drive cone cavity for thermal management 
(see Fig. 2a). However, in a CCA system the air in the rotor drive cone cavity is now significantly cooler than the compressor exit air. It is not desirable to bleed hot compressor exit air into the cavity as it will counteract the function of the CCA system. Indeed, the compressor exit air may, in future, be hot enough to cause thermal damage. One solution to this is to use a concept akin to that of a turbine "rim purge flow" which ensures that the hot, mainstream flow does not get ingested into rotor cavities. Essentially this means that flow is ejected into the mainstream from the rotor cavity (Fig. 2b). Unfortunately, the main gas path in compressors is generally more aerodynamically sensitive than in turbines and introduction of this purge flow may be more penalizing. This is particularly true of the compressor outlet guide (OGV) vanes and the pre-diffuser which turn and diffuse the flow. Both of these components have high aerodynamic loading and can therefore be prone to flow separation. Importantly, the OGV/pre-diffuser also form the interface with the combustor and it has been shown that the aerodynamic performance of these components can be closely coupled (see, for example, Walker et al. [3-5], Ford et al. [6]).

There have been many studies on the effects of ingress, leakage and rim purge flow in turbines but none, to date, specifically at the compressors-combustor interface. In turbines injection of coolant flow into the mainstream may be a necessity for thermal management but it must also be performed in such a way as to minimize any adverse aerodynamic effects. According to Sharma and Butler [7] 30-50\% of the losses in a turbine blade row are generated by secondary and end-wall flows. Ong et al. [8] state that cooling flows emanating from upstream cavities generally have less momentum 
and swirl than the mainstream flow reducing the angle of incidence onto the downstream vane. McLean et al. $[9,10]$ also state that radial injection of coolant can significantly alter the development of the hub-wall boundary layer. Clearly, both the change in angle of incidence and any radial velocity component have potential to alter the near wall and secondary flows. Indeed, in their numerical investigation Ong et al. [8] observed an increase in penetration of the secondary flows into the mainstream flow. However, by increasing the swirl angle of the injected flow they were also able to reduce the secondary flows and losses. Barigozzi et al. [11] observed similar results on an experimental rotor cascade. Negative injection ("swirl") angles were seen to enhance secondary flows whereas positive angles reduced the secondary flows. However, this was only observed at mass flow ratios (MFR) above $1 \%$ of the mainstream. Schrewe et al. [12] examined the effect of a rim seal flow on the main annulus flow in a low pressure two-stage turbine. The purge flow was located upstream of the second stage stator and five-hole probe measurements clearly showed that the core of the secondary flows deepens and moves inboard with increasing MFR (0-1.5\%). Schrewe et al. [12] summarized that, in general, the rim seal flow causes increased loss by (i) introducing a blockage as it enters the mainstream, (ii) intensifying the secondary flows, (iii) altering the incidence onto the downstream stage and (iv) subsequently altering the flow in the downstream stage.

Clearly the presence of a rim purge flow upstream of a compressor OGV has the potential to negatively affect the vane row and the pre-diffuser. However, perhaps of greater concern is the potential to affect the downstream combustor. Various authors 
[13-18] have shown that the inlet conditions presented to a combustor pre-diffuser have a crucial influence on its and the downstream combustor's aerodynamic performance. In a series of papers Walker et al. [3-5] examined component interaction within the compressor, pre-diffuser and combustor demonstrating the closely coupled nature of the system. A modest deterioration in the quality of the OGV/pre-diffuser flow was seen to cause a significant increase in system total pressure loss. This certainly suggests that a rim purge flow upstream on the OGV has potential to affect the combustion system aerodynamics.

\section{AIMS AND OBJECTIVES}

This paper has two main aims:

- To present a preliminary investigation into the effects of a purge flow that enters the main gas path immediately upstream of the OGV row.

- To investigate the use of swirl to improve the integration of the purge flow with the aerodynamics of the OGV/pre-diffuser.

Of interest to the work are the local aerodynamic effects on the OGV/prediffuser flow and the resulting effect on flow uniformity and total pressure loss in the combustion system. Minimal impact on this loss is crucial as this is closely linked to cycle performance and overall specific fuel consumption. The work utilizes a numerical (CFD) approach as a design tool and to investigate local effects in the OGV/pre-diffuser followed by use of a fully annular isothermal test facility to provide system performance data (velocity and pressure) via detailed area traverses of a miniature five-hole probe. 


\section{FULLY ANNULAR ISOTHERMAL TEST FACILITY}

Throughout the work an existing experimental facility was modified accordingly and used to recover aerodynamic data (Fig. 3). Housed within the Department of Aeronautical and Automotive Engineering at Loughborough University this rig comprises of a fully annular isothermal representation of a modern combustion system from the last stage of the HP compressor through to the inlet of the turbine. The test rig is described in more detail by Walker et al. [19] with only a cursory summary given here for completeness. Importantly the rig includes a bespoke $1 \frac{1}{2}$ stage axial flow compressor and an engine representative OGV. Although it is not possible to operate at engine conditions the test rig mass flow is set sufficiently high to ensure the OGV Reynolds number is greater than $1.9 \times 10^{5}$ (based on the OGV chord and the mean axial velocity at OGV inlet). According to Cumpsty [20] this means that and that boundary layer transition occurs early enough to ensure that the OGV exit flow (unsteady wakes and secondary flows) are fully representative of engine conditions. For all tests the compressor was operated at a fixed non-dimensional mass flow and non-dimensional rotor speed. At standard day conditions this amounts to a design speed of $4500 \mathrm{rpm}$ $\left(N / \sqrt{T_{01}}=265\right)$ and flow co-efficient $\left(\phi=V_{a} / U_{\text {blade }}\right)$ of 0.56 . This provides an air mass flow rate of approximately $3.3 \mathrm{~kg} / \mathrm{s}$, an inlet Mach number of 0.21 (i.e. incompressible) and an OGV Reynolds number of $2.0 \times 10^{5}$. The compressor non-dimensional speed and flow coefficient can be maintained to within $\pm 0.08 \%$ and $\pm 0.18 \%$ respectively of their prescribed values for the duration of the experiment. 
Downstream of the compressor the flow passes into the combustor test section via a pre-diffuser with an area ratio of 1.77 and a non-dimensional length of 3.1. The loading chart shown in Fig. 4 illustrates that the pre-diffuser sits above the "line-of-firststall" (as determined experimentally by Howard et al. [21] for diffusers with fully developed inlet conditions). In gas turbines this "line-of-first-stall" does not really represent a limit as the inclusion of compressor generated inlet conditions enables the pre-diffuser to operate closer to, and often above, the perceived stall margin due to the increased turbulence and secondary flows generated by the OGV row. The fuel injectors and flame tube are representative of current and near-term lean burn technology for medium to large civil aero engines. Note that to reduce complexity/cost flame tube cooling flows are not represented.

\section{Instrumentation, Data Reduction and Errors}

Throughout the test programme aerodynamic data were recovered using miniature five-hole pressure probes. Suitably calibrated and employed in the non-nulled mode, in line with Wray et al. [22], these provide the time-averaged local flow vector and total and static pressures. The probes could be traversed radially and circumferentially such that area traverses were constructed over repeatable sectors at OGV exit (A), pre-diffuser exit (B) and in the combustor annuli (C2 and E2) - refer to Fig. 3. For example, over an OGV the area traverse was constructed from $21 \times 21$ radial and circumferential measurement points with increased density in regions of interest such as the OGV wakes and boundary layers. From the five-hole probe data, at any given plane, spatially averaged values were obtained through suitable averaging as specified 
by Klein [23]. The spatially averaged velocity normal to the traverse plane ( $\bar{U})$ was area weighted whilst the total pressure $(\tilde{P})$ was mass-weighted, such that:

$$
\begin{gathered}
\tilde{P}=\tilde{p}+\alpha \frac{1}{2} \rho \bar{U}^{2} \\
\tilde{P}=\frac{1}{\dot{m}} \int P d \dot{m}, \alpha=\frac{1}{A} \int\left(\frac{U}{\bar{U}}\right)^{3} d A, \bar{U}=\frac{1}{A} \int U d A
\end{gathered}
$$

$\tilde{P}$ is the mass-weighted average pressure, $\bar{U}$ is the area-weighted average pressure and $\alpha$, the kinetic energy coefficient. The definition of a kinetic energy flux coefficient provides a method by which the distortion of the profile can be assessed; increasing from a value of unity as the profile distorts from uniformity. Changes in the spatially averaged pressures between any two planes are then expressed in terms of a total pressure loss, $\lambda$, and static pressure rise coefficient, $C p$, with the change being made non-dimensional by a suitable reference dynamic head, for example:

$$
\begin{aligned}
& \lambda=\frac{\tilde{P}_{1}-\tilde{P}_{2}}{\tilde{P}_{1}-\tilde{p}_{1}} \\
& C p=\frac{\tilde{p}_{2}-\tilde{p}_{1}}{\tilde{P}_{1}-\tilde{p}_{1}}
\end{aligned}
$$

The pressures measured were estimated to be accurate to within $1 \%$. The total velocity of the flow was obtained from the dynamic pressure, and hence the accuracy of the local velocities was within $\pm 0.5 \%$. Whilst the flow angle of the flow was determined from the calibration of the probe, additional errors in flow angle could arise associated 
with the ability of the user to align the probe within the test rig. However, it is estimated that this could be set to within $1^{\circ}$. In addition to the errors associated with the local measurements it was estimated that the mass weighted total and static pressures at a given traverse plane were repeatable to better than $10 \mathrm{Nm}^{-2}$. Thus, the repeatability of the derived total pressure loss and static pressure rise coefficients was better than \pm 0.005 . Additionally, the calculated mass flows at each traverse plane, derived from the velocity measurements, were all within $1 \%$ of each other. All measurements were corrected to ISA standard day conditions.

\section{PRELIMINARY PURGE FLOW INVESTIGATION}

\section{CFD Analysis and Design}

\section{Purge Flow Path}

Prior to entering the main gas path, the purge flow passes along the rotor drive cone and picks up tangential momentum and as such it will have reasonable swirl content when entering the main flow. In the test rig this was accomplished by allowing the flow to pass over the rotor disc as shown in Fig. 5. Although rotational Reynolds numbers cannot be matched in the low speed rig the compressor operates at the correct flow coefficient, so it is fair to assume that the purge flow will be broadly representative in terms of relative tangential momentum. Before committing to a test program, the suitability of the test rig design was investigated using a CFD and the basic model of the rotor cavity shown in Fig. 5 . The main objective of this was to assess the condition of the purge flow delivered to the main gas path and ensure that it was circumferentially uniform. A RANS CFD approach was adopted using the commercial 
solver ANSYS Fluent with a realizable k- $\varepsilon$ turbulence model, 2 nd order discretization, and enhanced wall treatment $(y+1-5)$ in order to resolve the boundary layers. The mesh had approximately 2 million cells with the rotor wall set to rotate at the test rig design speed. Convergence was determined by monitoring the rotor torque coefficient. Fig. 6 plots the circumferential variation in radial velocity, $\mathrm{V}$, normalized by the average axial velocity in the main gas path, $\bar{U}$, for a $1 \%$ MFR (i.e. the purge flow rate is equal to $1 \%$ of the mainstream flow). The data confirm that the purge flow should be circumferentially uniform, and no imprint of the delivery pipes seen. Similarly, Fig. 7 plots the axial variation of the purge flow at outlet and suggests that for a $1 \%$ MFR the purge flow will enter into the annulus with a relatively low radial velocity and a tangential velocity equal to approximately $70 \%$ of the mainstream axial velocity or $40 \%$ of the rotor blade speed.

\section{Purge Flow Location}

The location at which the purge flow enters the main gas will influence how it affects the aerodynamics of the OGV/pre-diffuser. Typically, in current engine designs, there is limited space between the rotor and OGV (see Fig. 2a) and the purge flow will be injected in close proximity to both the rotor and OGV. However, in the isothermal test rig there is an additional axial gap between the rotor and OGV to facilitate access for instrumentation (see Fig. 5). This results in the potential injection point moving almost a chord length upstream of the OGV. To assess this a CFD model was generated consisting of a single OGV sector modelled from rotor exit to diffuser exit (Fig. 8). The model included several slot locations through which the purge flow could be injected. 
Slot 1 was located immediately downstream of the rotor and slot 5 immediately upstream of the OGV. The downstream geometry was not included in order to reduce the computation expense. An unstructured mesh was employed consisting of approximately 3 million cells with prism layers used to control the near wall grid and maintain a wall $\mathrm{Y}+$ close to 1 . A RANS CFD approach was adopted using the commercial solver ANSYS Fluent, a realizable $k-\varepsilon$ turbulence closure, 2 nd order discretization and an enhanced wall treatment to resolve the boundary layers. Inlet boundary conditions were specified from existing measured rotor exit data with the purge flow inlet defined from the CFD model discussed above. It should be noted that the CFD model was validated using existing experimental data, without a purge flow, with both a grid dependency study and a turbulence model assessment performed. Convergence was determined by monitoring the total pressure loss coefficient in conjunction with examining the OGV wake development. By way of example Fig. 9 and 10 compare the CFD at OGV and pre-diffuser exit to the existing experimental data showing good agreement. The choice of modelling strategy is always a compromise between accuracy, cost and time. Ultimately, the flow is unsteady both spatially and temporally so a highfidelity model (e.g. LES) would be most appropriate for accuracy. However, in terms of cost and the fact that here a simplified model is used to design a test configuration it is more appropriate to use RANS approach. Several authors have shown that RANS can achieve good agreement with mean experimental data (see, for example, Paniagua et al. [24]). Similarly, the choice or turbulence closure is also dependent on the flow configuration. For turbomachinery applications $k-\omega S S T$ is perhaps the de facto RANS 
model but k- $\varepsilon$ models have also been shown to be successful [24]. Furthermore, that latter are known to be better for free-shear flows such as wake mixing in pre-diffusers and the complex free expansion into the downstream combustion system. For this region the authors' research group has found that a realizable $k-\varepsilon$ model performs slightly better in this type of flow. Certainly, the good comparison shown in Fig. 9 and 10 demonstrate that the current approach is fit-for-purpose.

Fig. 11 and 12 illustrate the effect of purge flow location on the predicted axial velocity contours at OGV and pre-diffuser exit. For a datum purge flow equal to $1 \%$ of the mainstream the data show that with the purge flow introduced immediately downstream of the rotor (slot 1 ) there is negligible effect. Conversely, immediately upstream of the OGV (slot 5) there is a notable increase in the size of the secondary flow loss core at OGV exit a degradation in the inner wall flow at pre-diffuser exit. This is in agreement with the observations of Ong et al. [7] Interestingly, Fig. 13 and 14 show that further increases in purge flow rate to $1.5 \%$ and $2 \%$ appears to have no significant additional effect. Clearly, this preliminary CFD highlights that, in order to simulate the engine geometry, the test rig needed further modification to introduce the purge flow immediately upstream of the OGV row - see Fig. 15.

\section{Experimental Results}

\section{Rotor Exit (Z)}

Five-hole probe measurements were taken at rotor exit over a $5^{\circ}$, two OGV sectors, for purge flows ranging from $0-3 \%$ of the main annulus flow. Fig. 16 illustrates that there is no measurable difference in the circumferentially averaged axial velocity 
profiles However, at higher purge flow rates some small differences do become apparent with the pitch angle increasing slightly and the yaw angle decreasing by $2^{\circ}$. This is not surprising as the purge flow presents an aerodynamic blockage on the inner casing. Importantly this suggests that the OGV will placed at an incidence it is not strictly designed for which has the potential to alter its performance. Additionally, the fact that the rotor slightly under turns at higher purge flows suggests that care is needed in future design to ensure rotor performance is not adversely affected. Particularly, as stated earlier, the rotor is likely to be closer to the purge flow slot in an actual engine.

OGV Exit $(A)$

Contours of normalized axial velocity measured, shown in Fig. 17, demonstrate that as the purge flow rate increases the effect on the OGV exit flow is gradual but clearly evident. The general flow characteristics remain the similar but, on the lower portion of the vane, the loss core increases and moves outboard. However, there is no evidence of the vane row stalling and the outer portion of the flow appears largely unchanged. This is also reflected in the circumferentially averaged profiles shown in Fig. 18. Below 1\% MFR differences are arguably within the resolution of the experiment. However, at higher flow rates the differences are certainly measurable, and the velocity profile becomes biased towards the outer casing and the OGV begin to under turn. At the highest MFR of $\sim 3 \%$ the OGV produce approximately $3^{\circ}$ less turning then the datum case with no purge flow. 
Pre-Diffuser Exit (B)

Data measured at pre-diffuser exit echo the results seen at OGV exit. Although the repeatable sector at pre-diffuser covers a complete burner-to-burner sector previous data have shown that, for the current geometry, the flow is not strongly influenced by the downstream combustor. Hence to save test time data were only taken over a $2.5^{\circ}$ sector covering a single OGV.

Velocity contours and circumferentially averaged profiles at pre-diffuser exit are presented in Fig. 19 and 20. With no purge flow the pre-diffuser exit has well developed boundary layers but the flow remains fully attached. The diffusion process plays a role in generating thickened boundary layers. The outboard cant of the pre-diffuser exacerbates this on the outer wall and the presence of the OGV loss cores degrades the flow on the inner wall. Overall this produces a slight outboard bias in the datum case and with increasing purge flow, and the corresponding increase in size of the OGV loss cores, the outboard bias grows further. However, despite the quality of the flow degrading the inner wall flow remains fully attached for all cases. Nevertheless, the purge flow will significantly alter the inlet condition to the combustor which, as will be seen later, alters the external aerodynamics total pressure loss in the combustion system.

Total Pressure Loss

Flow field plots have clearly shown that the purge flow alters the behavior of both the OGV and the pre-diffuser and thus changes the inlet conditions to the combustion system. The flow path in the combustor annuli is complex (see for example 
Ford at al [6]). The pre-diffuser efflux undergoes free expansion into the dump cavity, forming strong dump vortices with the resultant flow in the annuli is highly nonuniform. Consequently, on top of this already highly non-uniform flow it is difficult to see any impact of the purge flow in the combustor annuli. Nevertheless, the mass weighted total pressure loss coefficient, $\lambda$, does show degradation in system performance with increasing purge flow. This is plotted in Fig. 21 computed from rotor exit (Z) to each measurement location. The loss across both the OGV and pre-diffuser increase almost linearly as the purge flow increases the OGV loss cores. For the overall system (i.e. in the annuli and at combustor exit) the loss increases by about $4 \%$ at a low $1 \%$ MFR. This may be relatively small but given the ongoing drive to minimize combustion system loss this is still undesirable from an overall engine (SFC) perspective. However, at a $3 \%$ MFR the system loss increase is clearly unacceptably high at $13 \%$.

\section{PURGE FLOW WITH INCREASED SWIRL}

So far data have shown that the purge flow causes the OGV loss cores to increase in size which in turn deteriorates the downstream aerodynamics. In simple terms this is caused by a modification of the local flow vector at the hub altering the local OGV incidence, loading and hence performance. Fig. 7 suggests that the purge picks up around only $40 \%$ of the rotor blade speed as it passes up the rotor disc (i.e. $\mathrm{W} / \mathrm{U}_{\text {blade }} \sim 0.4$ ). This raises the question of if more (or less) swirl could be imparted onto the purge flow could the effect be reduced? 


\section{CFD Analysis}

The work used same single OGV sector and pre-diffuser model and CFD methodology as validated in the previous study (Fig. 7). To modify the purge flow inlet conditions the data shown in Fig. 7 were simply scaled to give differing MFR and swirl fraction, SF, which is defined as the purge flow mean swirl velocity divided by the rotor blade speed (W/U $\left./ U_{\text {blade }}\right)$. The range of MFR was nominally $0.5,1.0,1.5 \%$ and for the swirl fraction nominally $0.35,0.50,0.65$ and 0.75 .

Fig. 22 and 23 plot the axial velocity contours at OGV and pre-diffuser exit. It can be seen that the effects of MFR and swirl fraction are somewhat coupled but broadly speaking it is the swirl fraction that dictates the general nature of the effect and the MFR which sets the magnitude. At low swirl fraction the loss core is worse than the datum (no purge flow), degrading the inner wall flow and producing a more out board biased flow at pre-diffuser exit with an increased total pressure loss. Above a swirl fraction of 0.5 the loss core starts to visibly decrease in size and at a swirl fraction of 0.75 they appear almost nonexistent. However, as the MFR increases the increased purge flow causes a general thickening of the hub boundary layer which causes degradation of the pre-diffuser performance.

Fig. 24 compares the predicted flow field immediately upstream of the OGV for the highest MFR and swirl fraction against the datum case with no purge flow. Modifications to the flow field are limited to the hub region and the bulk of the flow approaching the OGV is not really affected. There is little change in the axial velocity except for a small thickening of the boundary layer. There is clear modification of the 
radial velocity close to the OGV and a clear, albeit thin, layer of flow close to the hub with increased swirl over the datum. The effect of this change in swirl is to modify the local incidence onto the OGV near the hub. Fig. 25 illustrates this qualitatively showing the mean streamlines close to the hub for MFR of $1 \%$. The arrow indicates the physical vane inlet angle and the plots clearly show that the local flow becomes better aligned to this the OGV inlet angle at the higher swirl fraction. The result of this can be seen in the contours of axial velocity plotted on a radial plane at $25 \%$ passage height in Fig. 26 . For the datum the suction surface flow is close to separation leading to the large loss core but at a swirl fraction of 0.75 , with the flow better aligned, the suction surface flow is much improved. However, the flow topology is not that simple as can be seen in Fig. 27. For the datum case the low momentum hub flow migrates up the vane as the rear section of the vane approaches separation and presents an aerodynamic blockage. This leads the center of the loss core being located roughly at $25 \%$ passage height. As the swirl fraction increases the approach angle improves and the rear portion of the vane is no longer under duress. With reduced aerodynamic blockage the hub streamlines do not now migrate and OGV wake is much thinner.

\section{Experimental Results}

\section{CFD Design of Rig Modifications}

To experimentally evaluate the effect of increased swirl fraction on the overall system performance the test rig first had to be modified from that shown in Fig. 15 to introduce some pre-swirling nozzles. The basic concept used is illustrated in Fig. 28 with CFD used to finalize the contraction ratio and angle needed to produce the desired swirl 
fraction. Results from this study (Koli and Walker [25]) are not shown but used the same CFD methodology described previously. Fig. 28 summarizes the final design parameters for the nozzles used in the test rig and gives details of the predicted swirl fraction for each design for an MFR of $1 \%$ and $1.5 \%$. Importantly the CFD results showed that the nozzle design, with one nozzle for every two OGV, produced a circumferentially uniform flow at entry to main gas path. However, one caveat of the nozzle design is that it wasn't possible in the test rig to measure the swirl fraction and for all the data presented the swirl fraction is that seen in the CFD.

\section{OGV Exit (A) and Pre-Diffuser Exit (B)}

Data are not presented for rotor exit since the previous tests showed that the purge flow had no notable effect on the flow at measured rotor exit. For OGV exit and pre-diffuser exit five-hole probe area traverses conducted at OGV exit axial velocity contours are presented in Fig. 29 and 30. Data were recorded for the pre-swirl nozzle designs detailed in Fig. 28 and for a MFR of 1\% and 1.5\%. Data were only recorded over a single OGV sector as previous results indicated no differences between neighboring OGV. The experimental data show the same trends as the CFD but the magnitude of the effect is much smaller. At the lowest swirl fraction the loss core at OGV exit is again seen to slightly increase and then reduce as the swirl fraction increases. It is difficult to say whether it is the CFD that over predicts the effect or the fact that test rig perhaps doesn't generate the required level of swirl. Nevertheless, the same trends are evident. At pre-diffuser exit the measured changes are subtle and again much smaller in magnitude than predicted in the CFD. In reality, it is difficult argue whether any of the 
small differences are due to experimental uncertainty or are indeed a result of the varying swirl fraction of the purge flow.

\section{Total Pressure Loss}

The flow field data presented in Fig. 29 and 30 show only subtle changes which could be argued follow the trend seen in the CFD. However, the total pressure loss data provide more supporting evidence of the effect of the purge flow. In order to save test time, the loss data presented in Fig. 31 was calculated by measuring the pressure drop across the metering plate at the rear of the rig in conjunction with a rotor exit five-hole probe traverse. This removed the need to perform numerous five-hole area traverses in the combustor annuli. The data are presented normalized by the datum loss coefficient and in this way quickly highlight if the system performance improves or degrades with purge flow rate and swirl fraction.

It can now be seen that the system pressure loss follows the trends in the flow field predicted in the CFD. At low swirl fractions the purge flow puts the hub of the OGV at increased incidence resulting in larger loss cores and reduction is the quality of the flow at pre-diffuser exit. This results in increase in system loss of $1-2 \%$ over the datum system with no purge flow. As the purge flow rate increases and the flow is better aligned with the leading edge of the OGV (at the hub) the loss cores reduce and the prediffuser efflux improves. This results in a reduction in the system loss in the order of $10 \%$ which is significant. As the purge flow predominately affects the hub flow the loss data show that the inner annulus losses are consequently more affected than the outer. 
For example, at an MFR or $1 \%$ and a swirl fraction of 0.65 the HGV inner bleed loss is reduced by $14 \%$ whereas the outer NGV bleed only sees a $5 \%$ improvement.

\section{CONCLUSIONS}

The work presented herein represents an investigation into the effects of a rim purge flow which enters the main gas path immediately upstream of the high-pressure compressor outlet guide vane row. Initial CFD predictions demonstrated the potential of the purge flow to negatively affect the aerodynamics of the OGV. Secondary loss cores were seen to increase with the purge flow rate and consequently the pre-diffuser exit flow (i.e. the inlet condition to the combustion system) deteriorated. Experimental assessment using a suitably modified fully annular, isothermal test facility confirmed the preliminary CFD results. However, at a typical purge flow rate, equal to $\sim 1 \%$ of the mainstream flow, the effects on the measured combustion system loss was small, increasing by $\sim 4 \%$. Nevertheless, at higher purge flow rates (up to $3 \%$ ) the effects became unacceptable; the OGV/pre-diffuser flow degraded significantly with a resultant $13 \%$ increase in the combustion system loss.

To try and mitigate this, or even improve the OGV hub flow, CFD was used to examine the effect of varying in the purge flow swirl fraction in conjunction to the mass flow rate. At lower swirl fractions ( $\sim 0.35$ times the rotor speed) the local OGV incidence close to the hub was increased such that the generation of loss cores through the OGV row was magnified. Increasing the swirl fraction ( 0.65$)$ better aligned the hub flow with the OGV leading edge and the loss core reduced in size below that of the datum case 
(with no purge flow). At higher swirl fractions ( 075) the loss cores were generated closer to the hub and the hub wall boundary layer became significantly thicker leading to the inner wall of the pre-diffuser being close to separation. For a given swirl fraction increasing the purge flow rate had only a small effect on the loss core but, in general, resulted in a thicker hub boundary layer. Experimental assessment on the annular rig showed similar trends to the CFD but the effects on the flow field had a smaller magnitude. However, differences in system loss were observed with savings of around $10 \%$ measured at the turbine feed ports with a mass flow ratio of $1 \%$ and a swirl fraction of 0.65 .

If a purge flow is required from the drive cone cavity then it is clear this can have a negative effect on the OGV/pre-diffuser flow and overall system performance. However, if the purge flow is pre-swirl to better match the OGV inlet angle near the hub then the OGV/pre-diffuser flow and overall system performance can be improved. 
Influence of Purge Flow Swirl at Exit to the High-Pressure Compressor on OGV/Pre-Diffuser and Combustion System Aerodynamics

\section{ACKNOWLEDGMENT}

The authors would like to thank Dr. Paul Denman for his work in developing the annular rig experimental infrastructure and data acquisition software. In addition, the authors would also like to thank the UTC Technicians (A Fardoe, L Monk, B Niven and N Thorley) for their help assembling and maintaining the test facility.

\section{FUNDING}

This research was undertaken at Loughborough University within the Rolls-Royce University Technology Centre (UTC) in Combustion System Aero Thermal Processes. It was funded by Rolls-Royce as part of SILOET II (Strategic Investment in Low-carbon Engine Technology) Project 18 - Future Core Engine Systems. 


\section{NOMENCLATURE}

\begin{tabular}{|c|c|}
\hline$A$ & Area \\
\hline$A R$ & Area ratio \\
\hline CCA & Cooled Cooling Air \\
\hline$C p$ & Static pressure recovery coefficient \\
\hline$h$ & Passage height \\
\hline IGV & Inlet guide vane \\
\hline$L$ & Length \\
\hline MFR & Mass flow ratio \\
\hline$\dot{m}$ & Mass flow rate \\
\hline$N$ & Rotor speed \\
\hline OGV & Outlet guide vane \\
\hline$P, p$ & Total, static pressure \\
\hline$r_{i}$ & Inner wall (hub) radius \\
\hline$r_{0}$ & Outer wall (casing) radius \\
\hline SF & Swirl fraction \\
\hline$U_{\text {blade }}$ & Mid-height blade speed \\
\hline$U, V, W$ & Axial, radial and tangential velocity components in cylindrical polar co- \\
\hline
\end{tabular}


$Y_{+}$

$\rho$

$\phi$

$\lambda$

Superscripts Axial distance

Dimensionless wall distance

Density

Flow coefficient ( $\left.\mathrm{V}_{\text {axial }} / \mathrm{U}_{\text {blade }}\right)$

Total pressure loss coefficient

Area-weighted spatial average

Mass-weighted spatial average

\section{Subscripts}

Z

Rotor exit

$A$

OGV exit

$B$

Pre-diffuser exit

C2

Combustor inner annulus

E2

Combustor outer annulus

1,2

Generic inlet, exit stations 
Influence of Purge Flow Swirl at Exit to the High-Pressure Compressor on OGV/Pre-Diffuser and Combustion System Aerodynamics

\section{REFERENCES}

[1] Advisory Council Aviation Research and Innovation in Europe, 2011, “Flightpath 2050

- Europe's Vision for Aviation", ISBN 978-92-79-19724-6

http://ec.europa.eu/transport/modes/air/doc/flightpath2050.pdf

[2] Wilfert, G., Sieber, J., Rolt, A., Baker, N., Touyeras, A., and Colantuoni, S., 2007, “New Environmentally Friendly Aero Engine Core Concepts," ISABE Paper No. 2007-1120.

[3] Walker, A. D., Carrotte, J. F. and McGuirk, J. J., 2007, “Enhanced External Aerodynamic Performance of a Generic Combustor Using and Integrated OGV/PreDiffuser Design Technique", ASME J. Eng. Gas Turbines Power, 129(1), p.80-87.

[4] Walker, A. D., Carrotte, J. F. and McGuirk, J. J., 2008, “Compressor / Diffuser / Combustor Aerodynamic Interactions in Lean Module Combustors", ASME J. Eng. Gas Turbines Power, 130(1), p.011504.

[5] Walker, A. D., Carrotte, J. F. and McGuirk, J. J., 2009, "The Influence of Dump Gap on External Combustor Aerodynamics at High Fuel Injector Flow Rates", ASME J. Eng. Gas Turbines Power, 131(3), p.031506. 
[6] Ford, C. L., Carrotte, J. F. and Walker, A. D., 2012, "The Impact of Compressor Exit Conditions on Fuel Injector Flows", ASME J. Eng. Gas Turbines Power, 134(11), p.111504.

[7] Sharma, O. P., and Butler, T. L., 1987, "Predictions of Endwall Losses and Secondary Flows in Axial Flow Turbine Cascades", ASME J. Turbomach., 109(2), p.229-236.

[8] Ong, J., Miller, R. J., and Uchida, S., 2012, "The Effect of Coolant Injection on the Endwall Flow of a High Pressure Turbine", ASME J. Turbomach., 134(5), p.051003.

[9] McLean, C., Camci, C., and Glezer, B., 2001, "Mainstream Aerodynamic Effects Due to Wheelspace Coolant Injection in a High-Pressure Turbine Stage. Part I: Aerodynamic Measurements in the Stationary Frame", ASME J. Turbomach., 123(4), p.687-696.

[10] McLean, C., Camci, C., and Glezer, B., 2001, “Mainstream Aerodynamic Effects Due to Wheelspace Coolant Injection in a High-Pressure Turbine Stage. Part II: Aerodynamic Measurements in the Rotational Frame", ASME J. Turbomach., 123(4), p.697-703.

[11] Barigozzi, G., Franchini, G., Perdichizzi, A., Maritano, M., and Abram, R., 2014, "Influence of Purge Flow Injection Angle on the Aero-Thermal Performance of a Rotor Blade Cascade", ASME J. Turbomach., 136(4), p.041012. 
[12] Schrewe, S., Werschnik, H., and Schiffer, H., 2013, "Experimental Analysis of the Interaction Between Rim Seal and Main Annulus Flow in a Low Pressure Two Stage Axial Turbine", ASME J. Turbomach., 135(5), p.051003.

[13] Stevens, S. J., Nayak, U. S. L., Preston, J. F. and Scrivener, C. T. J., 1978, "Influence of Compressor Exit Conditions on Diffuser Performance", J. of Aircraft, 15(8). P.482-488.

[14] Stevens, S. J. and Williams, G. J., 1980, "The Influence of Inlet Conditions on the Performance of Two Annular Diffusers", ASME J. of Fluids Eng., 102(3), p.357-363.

[15] Stevens, S. J., Harasgama, S. P. and Wray, A. P., 1984, "The Influence of Blade Wakes on Combustor Shortened Pre-diffusers", J. of Aircraft, 21(9), p.641.

[16] Zierer, T., 1993, "Experimental Investigation of the Flow in Diffusers Behind an Axial Flow Compressor", ASME Paper No. 93-GT-347.

[17] Barker, A. G., and Carrotte, J. F., 2001, "The Influence of Compressor Exit Conditions on Combustor Annular Diffusers - Part I: Diffuser Performance", AIAA J. of Propulsion and Power, 17(3), p.678-686. 
[18] Barker, A. G., and Carrotte, J. F., 2001, "The Influence of Compressor Exit Conditions on Combustor Annular Diffusers - Part II: Flow Redistribution Within the Diffuser", AIAA J. of Propulsion and Power, 17(3), p.687-695.

[19] Walker, A. D., Koli, B., Liang, G., Beecroft, P., and Zedda, M., 2017, “Impact of a Cooled Cooling Air System on the External Aerodynamics of a Gas Turbine Combustion System", ASME J. Eng. Gas Turbines Power, 139(5), p.051504.

[20] Cumpsty, N. A., 1989, Compressor Aerodynamics, Longman Scientific and Technical, Harlow, Essex, UK.

[21] Howard, J. H. G., Henseler, H. J. and Thornton-Trump, A. B., 1967, “Performance and Flow Regimes for Annular Diffusers", ASME Paper 67-WA/FE-21.

[22] Wray, A. P. and Carrotte, J. F., 1993, "The Development of a Large Annular Facility for Testing Gas Turbine Combustor Diffuser Systems", AIAA-93-2546.

[23] Klein, A., 1995, "Characteristics of combustor diffusers", Progress in Aerospace Science, 31(3), p.171-271. 
[24] Paniagua, G., Dénos, R., and Almeida, A., 2004, “Effect of the Hub Endwall Cavity Flow on the Flow-Field of a Transonic High-Pressure Turbine", ASME J. Turbomach., 126(4), p.578-586.

[25] Koli, B., and Walker, A.D., 2016, “SILOET II Project 18 Deliverable 2.2.6 CCA HP System Purge Flow Optimzation - CFD", Report TT/UTC/16/R32, Department of Aeronautical and Automotive Engineering, Loughborough University, UK. 


\section{FIGURES}

Fig. 1 Cooled cooling air concept [2]

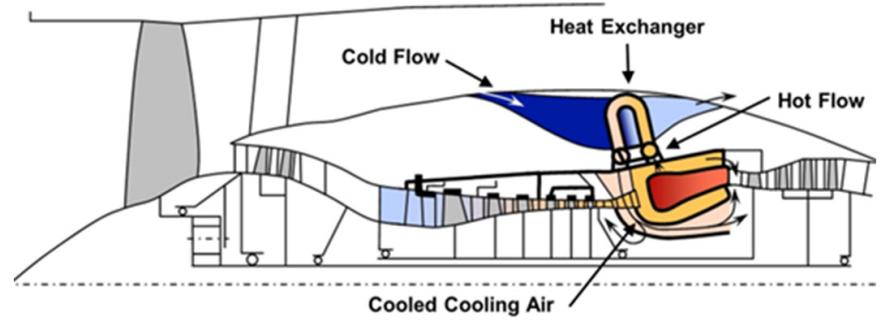

Fig. 2 Secondary air systems - compressor exit
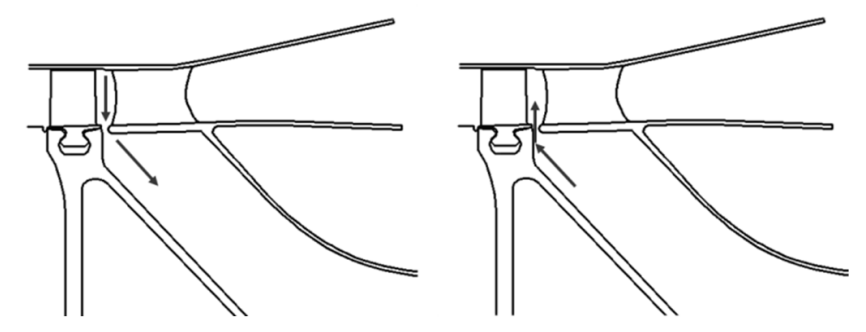

(a) Conventional "outflow"

(b) Proposed "purge" flow

Fig. 3 Test rig cross section

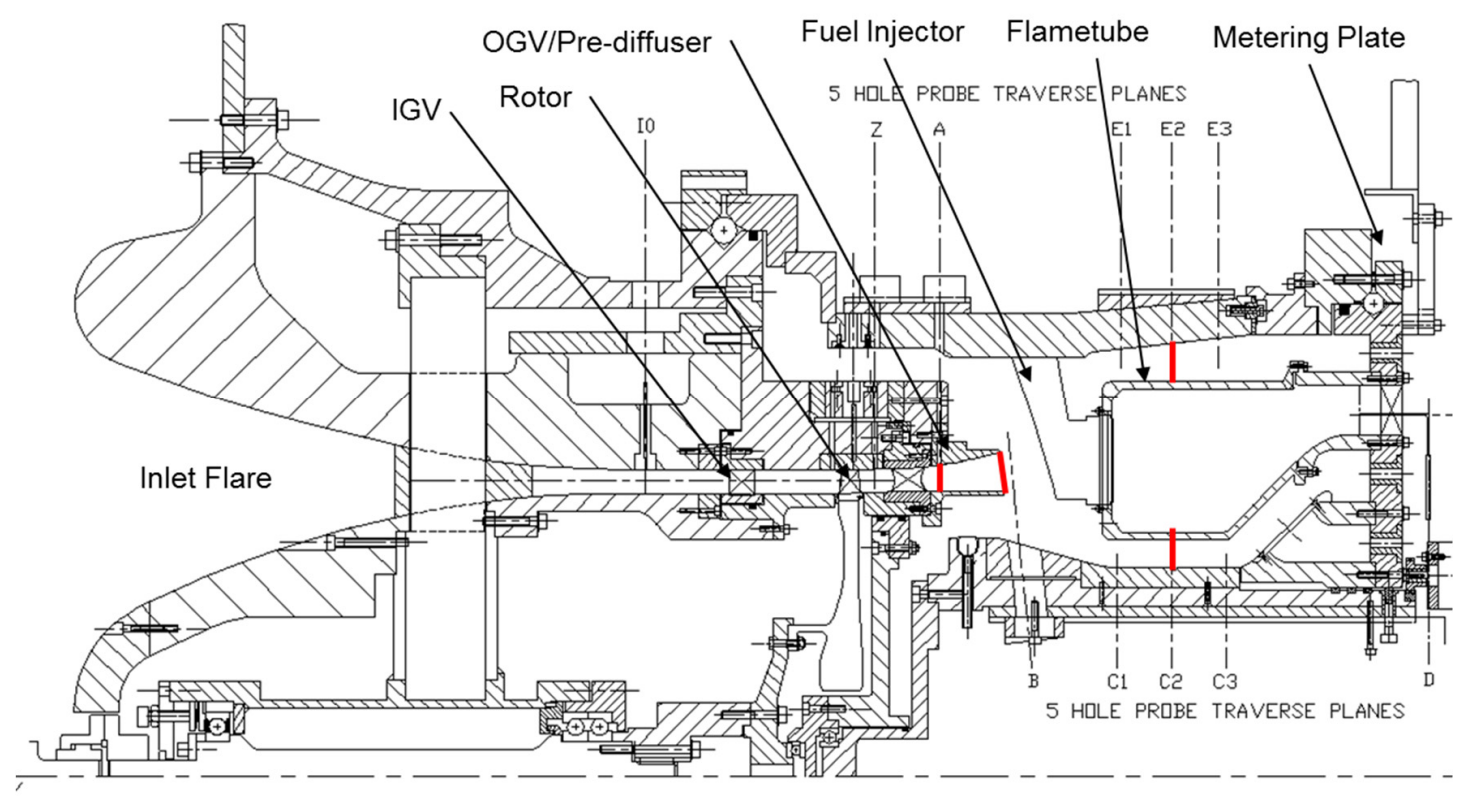


Fig. 4 Typical pre-diffuser loading chart $[19,21]$

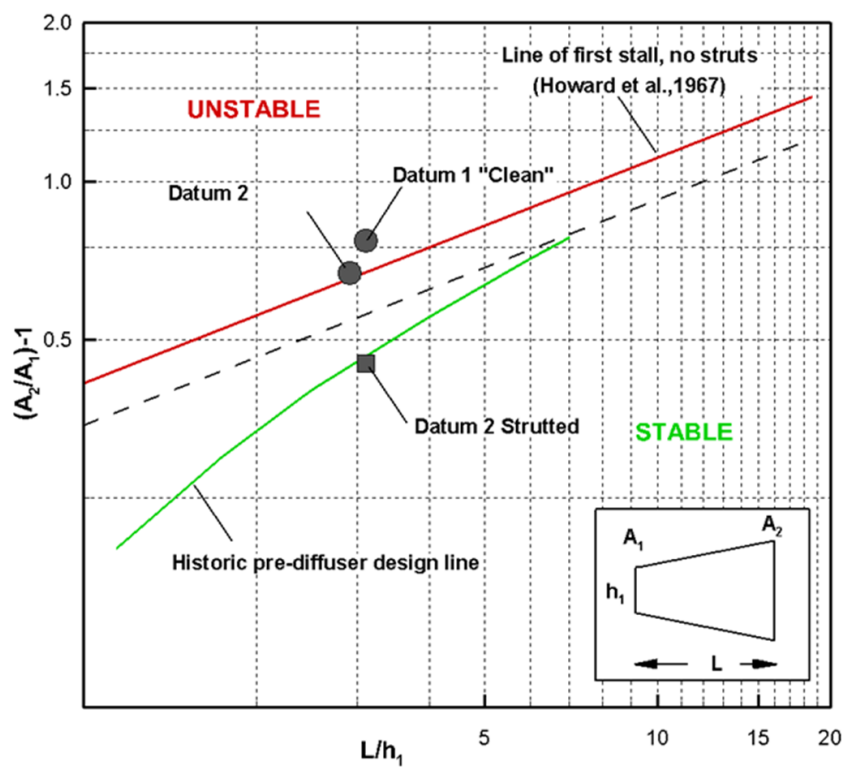

Fig. 5 Purge flow path (test rig and CFD model)
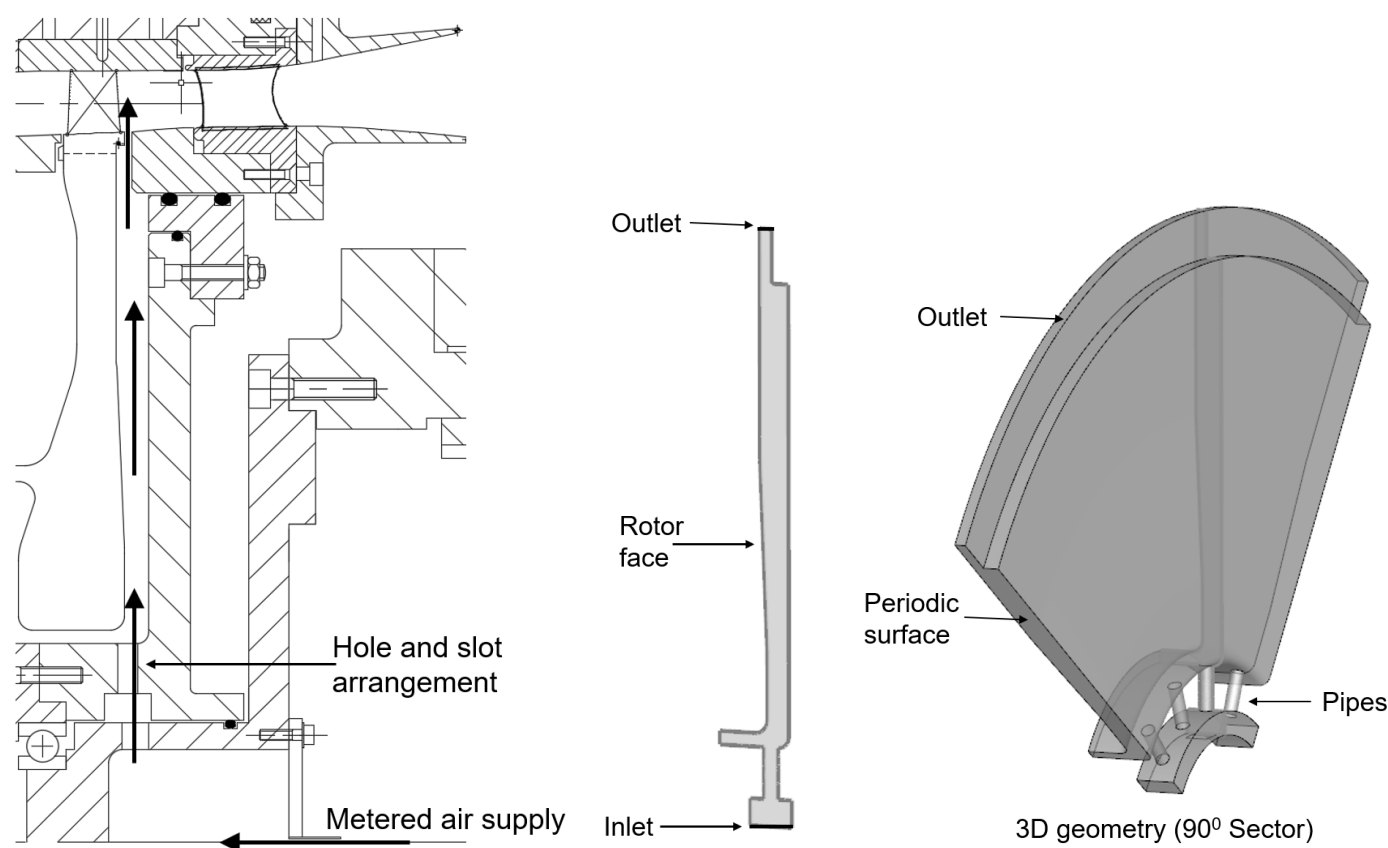

3D geometry $\left(90^{\circ}\right.$ Sector $)$ 
Fig. 6 Circumferential variation in purge flow (1\% MFR)

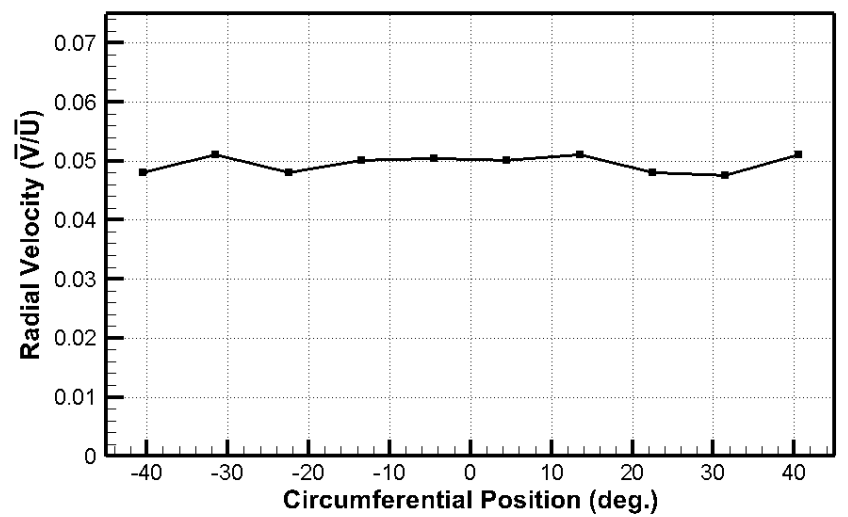

Fig. 7 Axial variation on purge flow (1\% MFR)
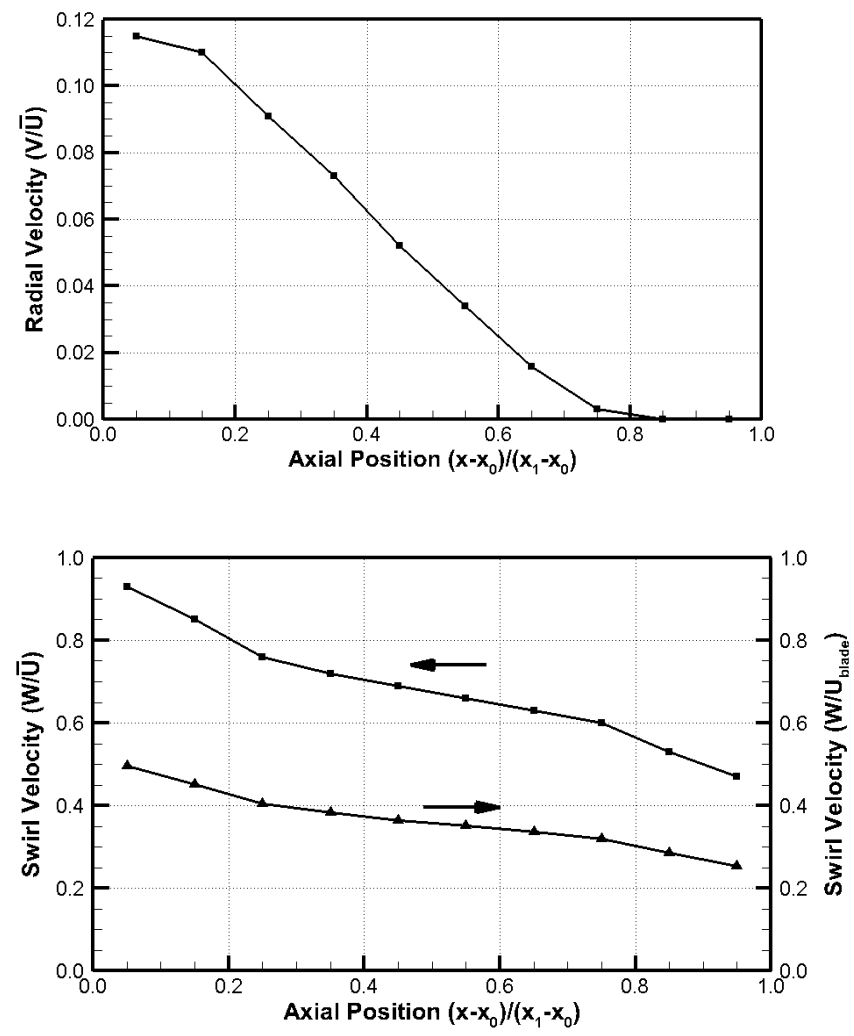
Fig. 8 OGV/pre-diffuser CFD model

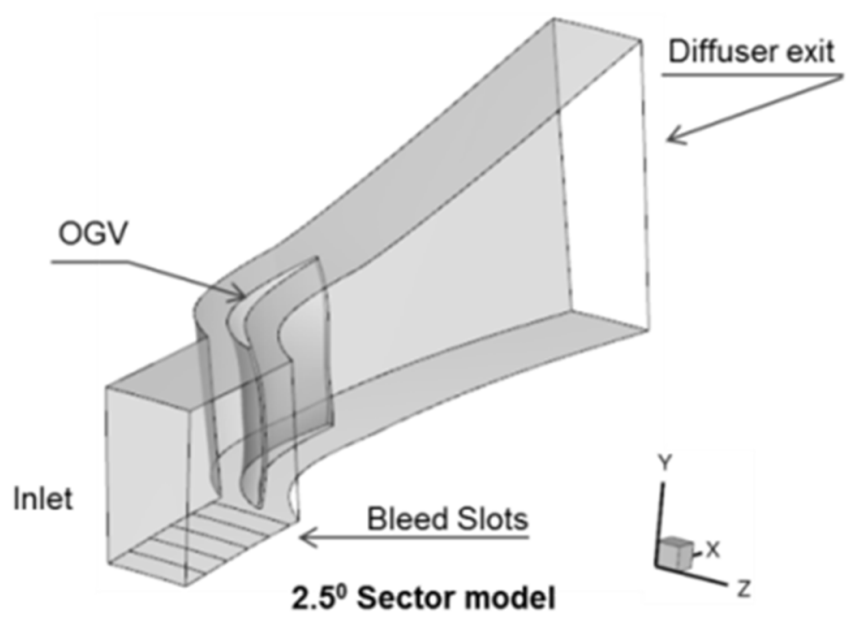

\begin{tabular}{|c|c|}
\hline \multicolumn{2}{|l|}{ Purge flow } \\
\hline Mass flow rate & MFR $=0-3 \%$ ( $\%$ of mainstream flow) \\
\hline Cavity gap ratio & $\sim 0.18$ (axial gap/annulus height) \\
\hline Rotational Re & $\begin{array}{l}\sim 5 \times 10^{6} \text { (based rotor speed and } \\
\text { hub diameter) }\end{array}$ \\
\hline \multicolumn{2}{|l|}{ OGV } \\
\hline Turning & $\sim 45^{\circ}$ (mid-height) \\
\hline Diffusion factor & $\sim 0.45$ (mid-height) \\
\hline $\operatorname{Re}$ & $\sim 2 \times 10^{5}$ (based on chord) \\
\hline \multicolumn{2}{|l|}{ Pre-diffuser } \\
\hline Area ratio & $\mathrm{AR}_{\mathrm{A}-\mathrm{B}} \sim 1.7$ \\
\hline Length & $\mathrm{L}_{\mathrm{A}-\mathrm{B}} / \mathrm{h}_{\mathrm{A}}=3.1$ \\
\hline
\end{tabular}


Fig. 9 CFD validation - no purge flow - OGV exit

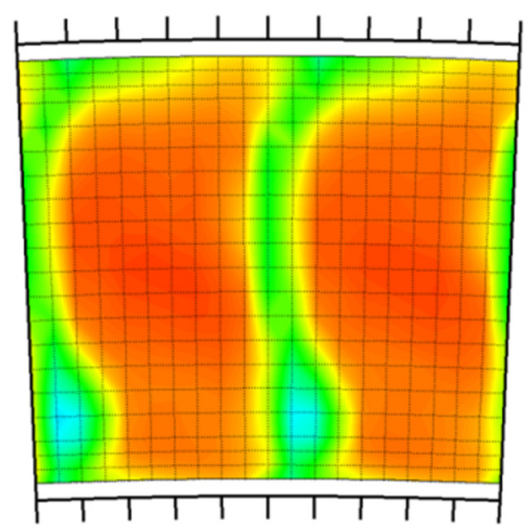

(a) Experiment

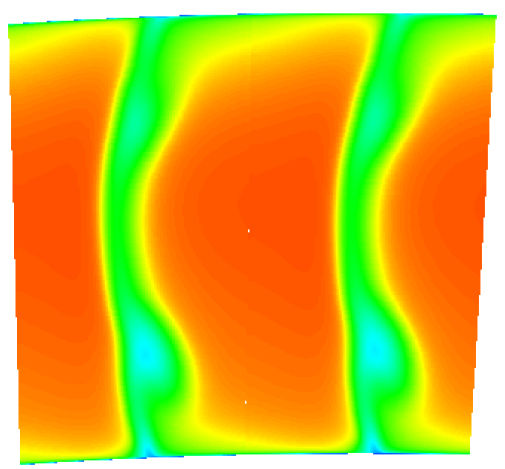

(b) CFD

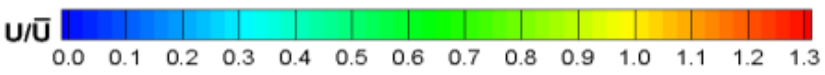

Fig. 10 CFD validation - no purge flow - diffuser exit

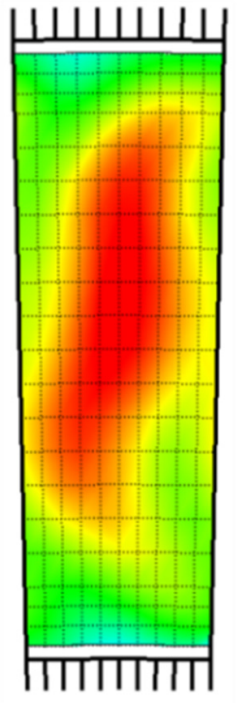

(a) Experiment
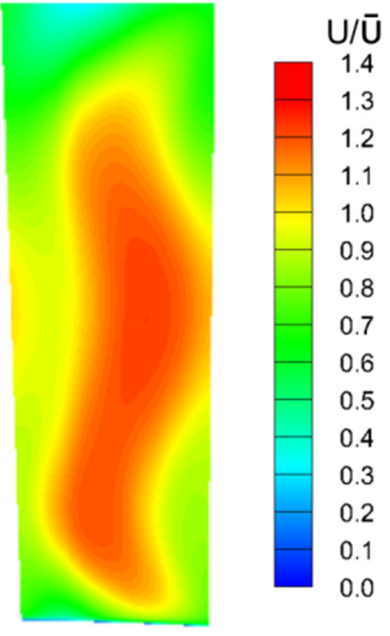

(b) CFD 
Fig. 11 Effect of purge flow location (CFD) - 1\% MFR - OGV exit
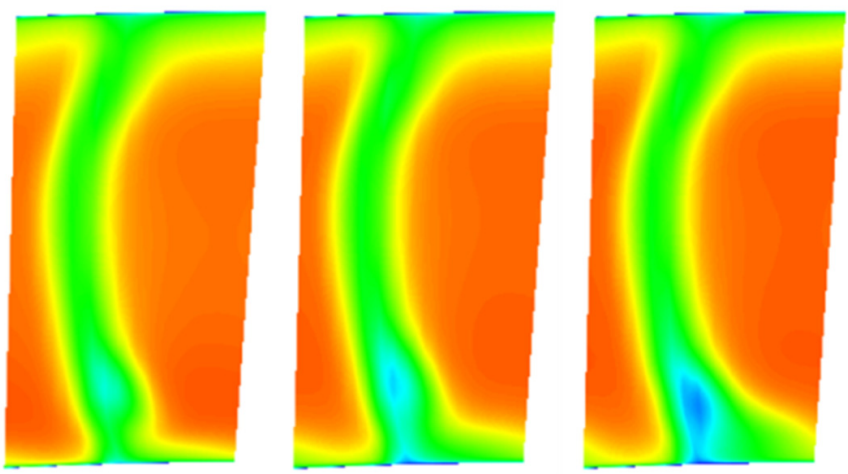

U/Ū

$\begin{array}{llllllllllllll}0.0 & 0.1 & 0.2 & 0.3 & 0.4 & 0.5 & 0.6 & 0.7 & 0.8 & 0.9 & 1.0 & 1.1 & 1.2 & 1.3\end{array}$
(a) Slot 1
(b) Slot 3
(c) Slot 5

Fig. 12 Effect of purge flow location (CFD) - 1\% MFR - diffuser exit
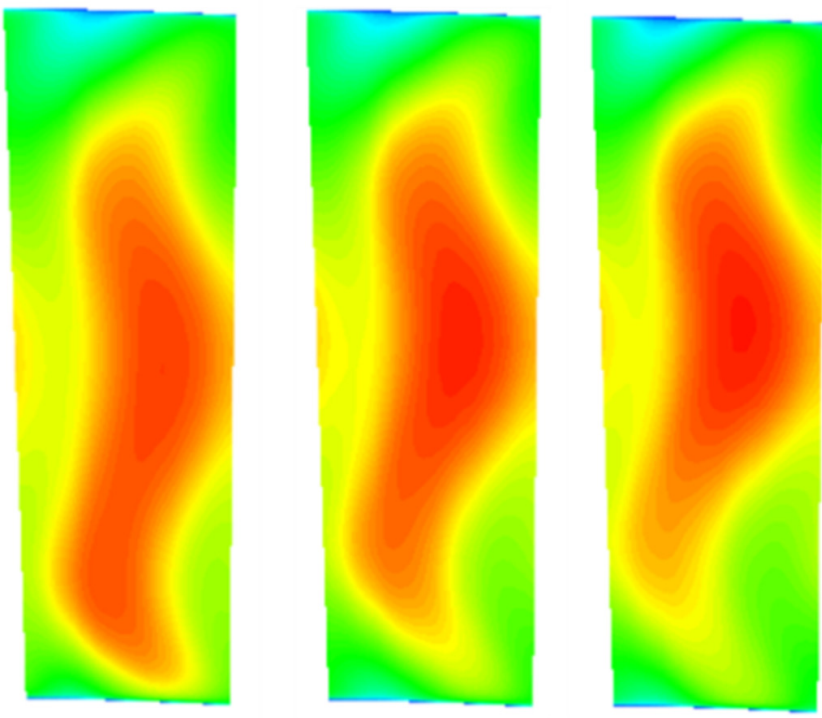

$U / \overline{\mathbf{U}}$
$\begin{array}{lll}0.0 & 0.1 & 0.2\end{array}$

(a) Slot 1

(b) Slot 3

(c) Slot 5 
Fig. 13 Effect of purge flow rate (CFD) - slot 5 - OGV exit
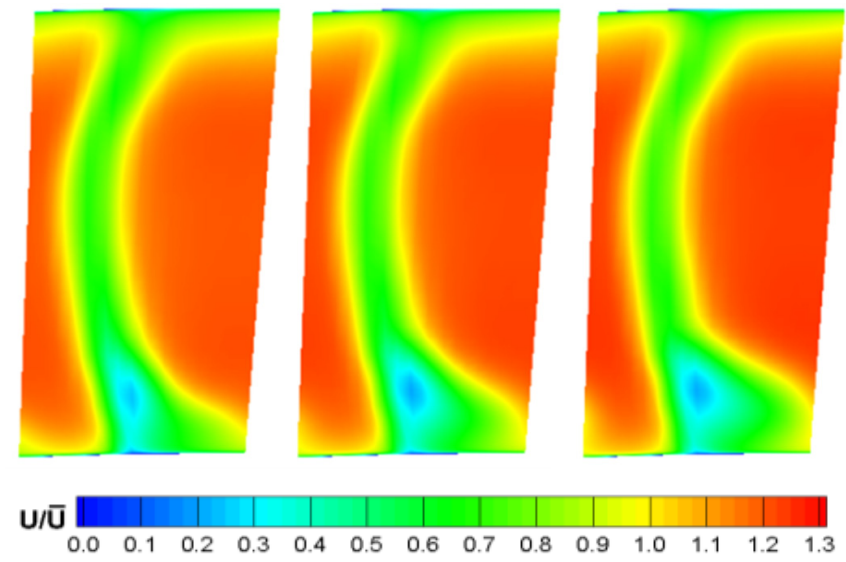
(a) $1 \%$
(b) $1.5 \%$
(c) $2 \%$

Fig. 14 Effect of purge flow rate (CFD) - slot 5 - diffuser exit

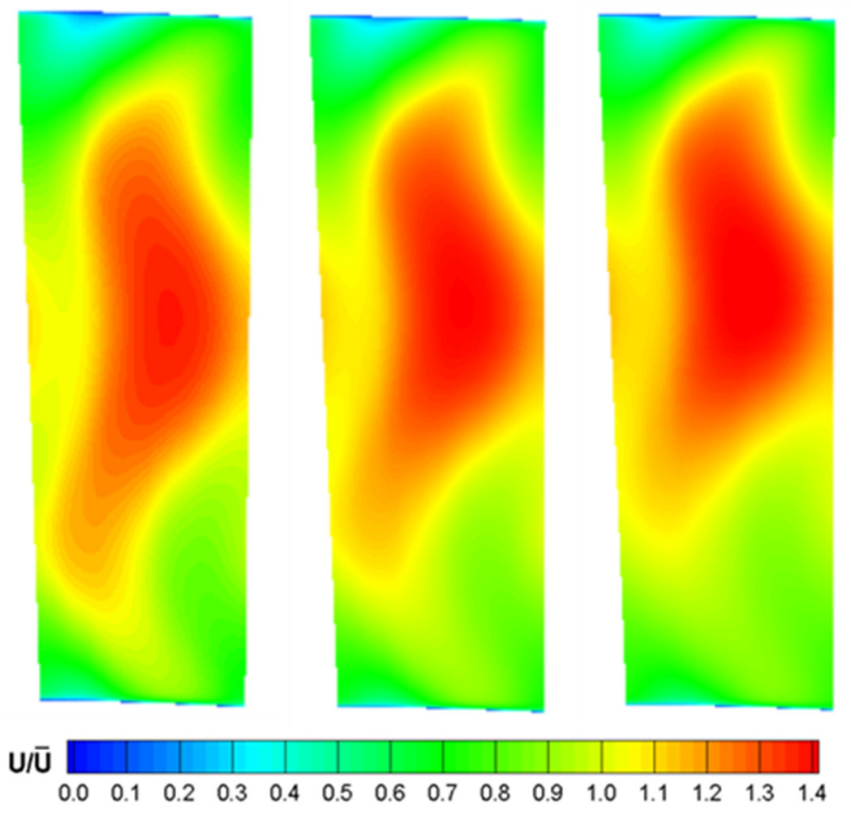
(a) $1 \%$
(b) $1.5 \%$
(c) $2 \%$ 
Fig. 15 Final test rig configuration

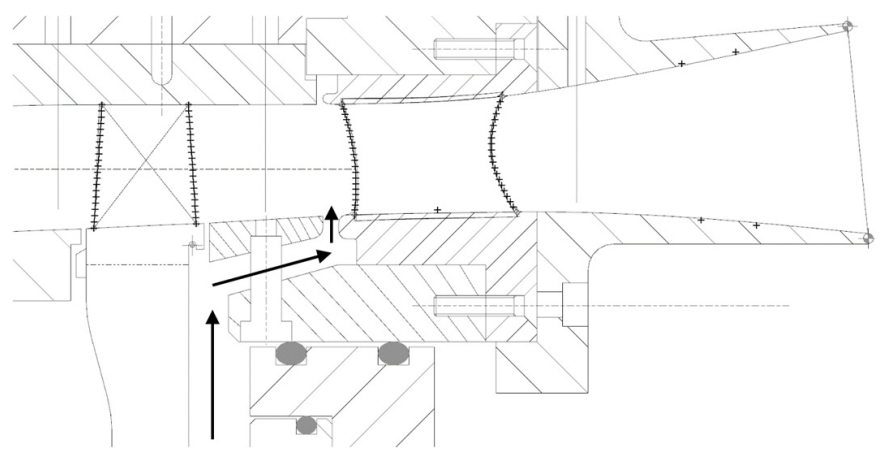

Fig. 16 Circumferentially averaged profiles at rotor exit for varying MFR
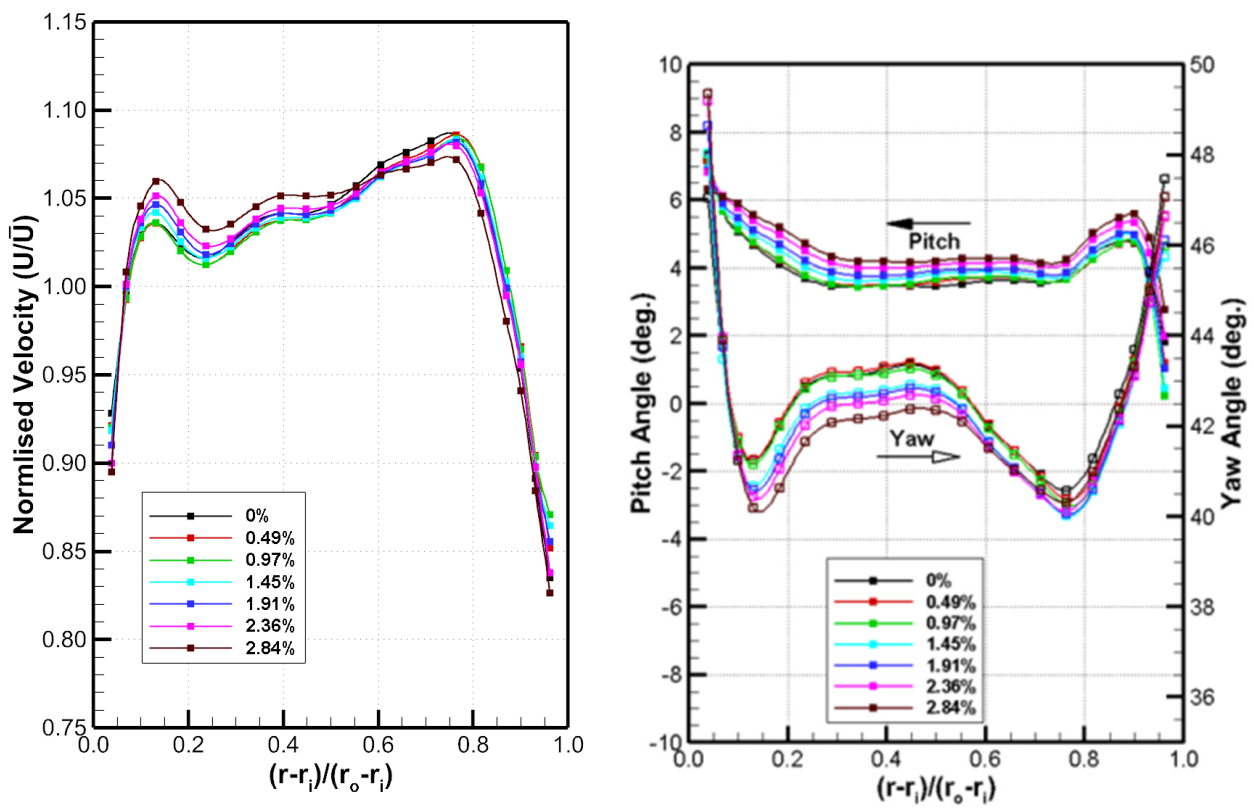
Fig. 17 Contours of axial velocity at OGV exit for varying MFR

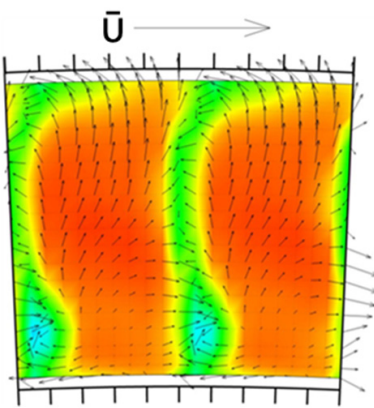

(a) $0 \%$

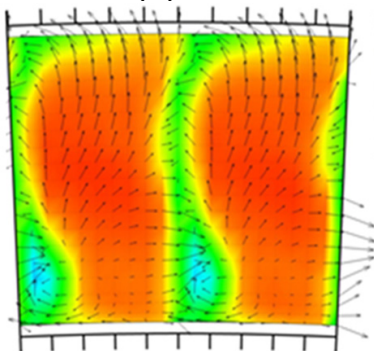

(c) $0.97 \%$

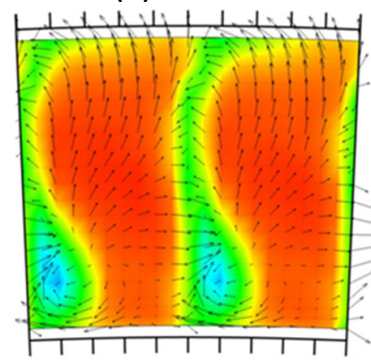

(e) $1.91 \%$

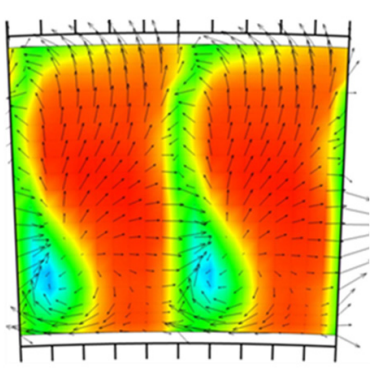

(g) $2.84 \%$

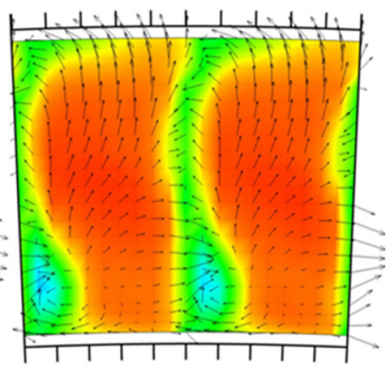

(b) $0.49 \%$

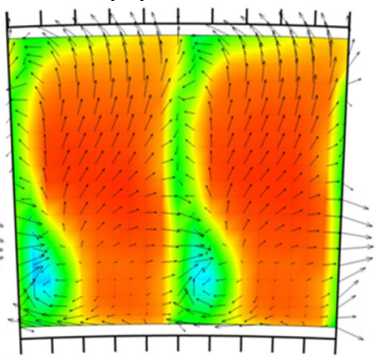

(d) $1.45 \%$

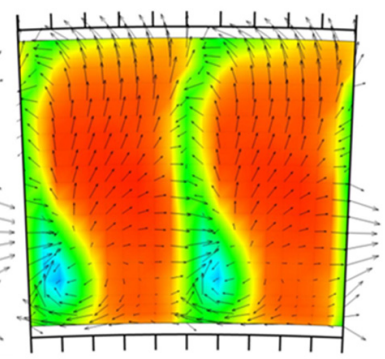

(f) $2.36 \%$

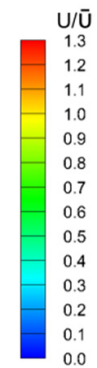


Fig. 18 Circumferentially averaged profiles at OGV exit for varying MFR
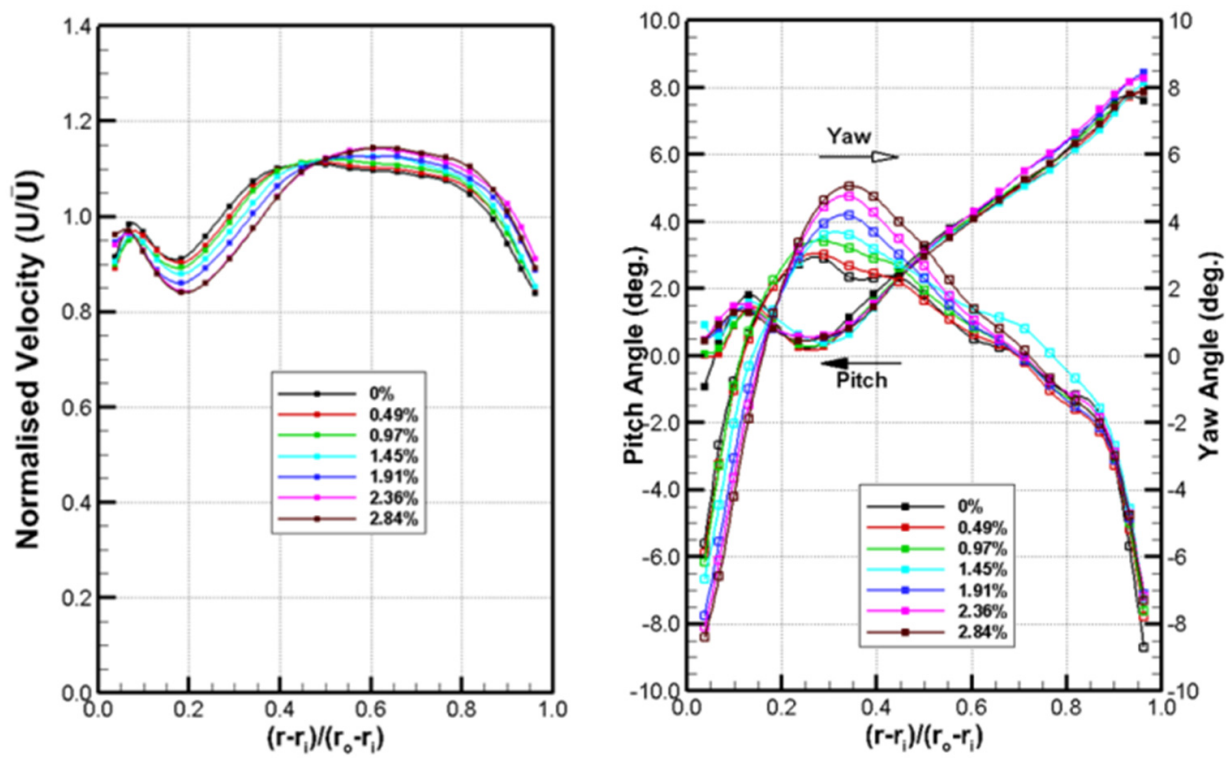
Fig. 19 Contours of axial velocity at diffuser exit for varying MFR
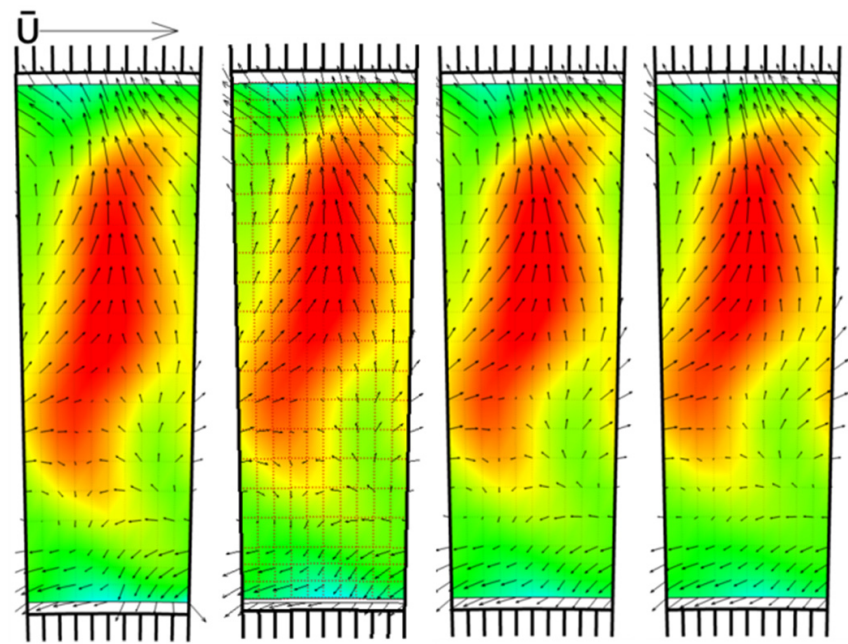

(a) $0 \%$

(b) $0.49 \%$

(c) $0.97 \%$

(d) $1.45 \%$
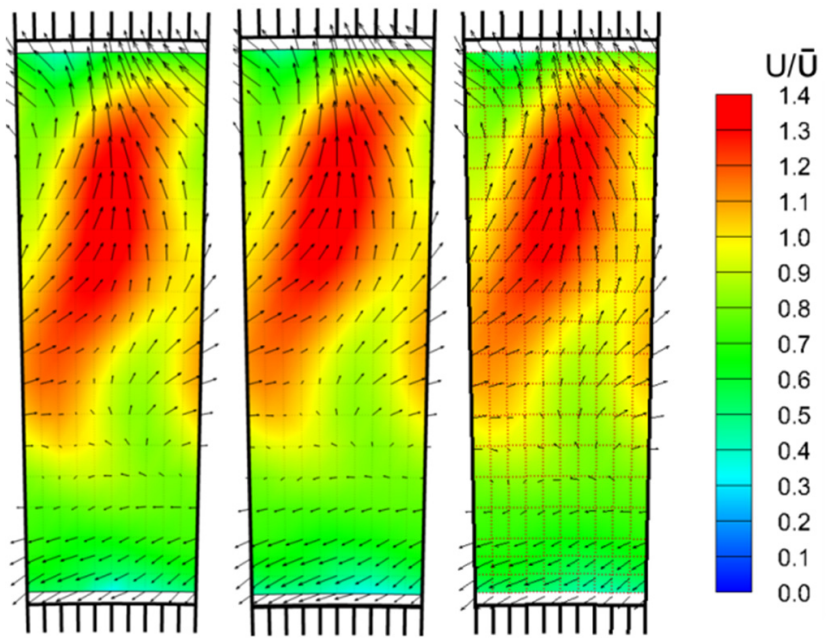
(e) $1.91 \%$
(f) $2.36 \%$
(g) $2.84 \%$ 
Fig. 20 Circumferentially averaged profiles at diffuser exit for varying MFR
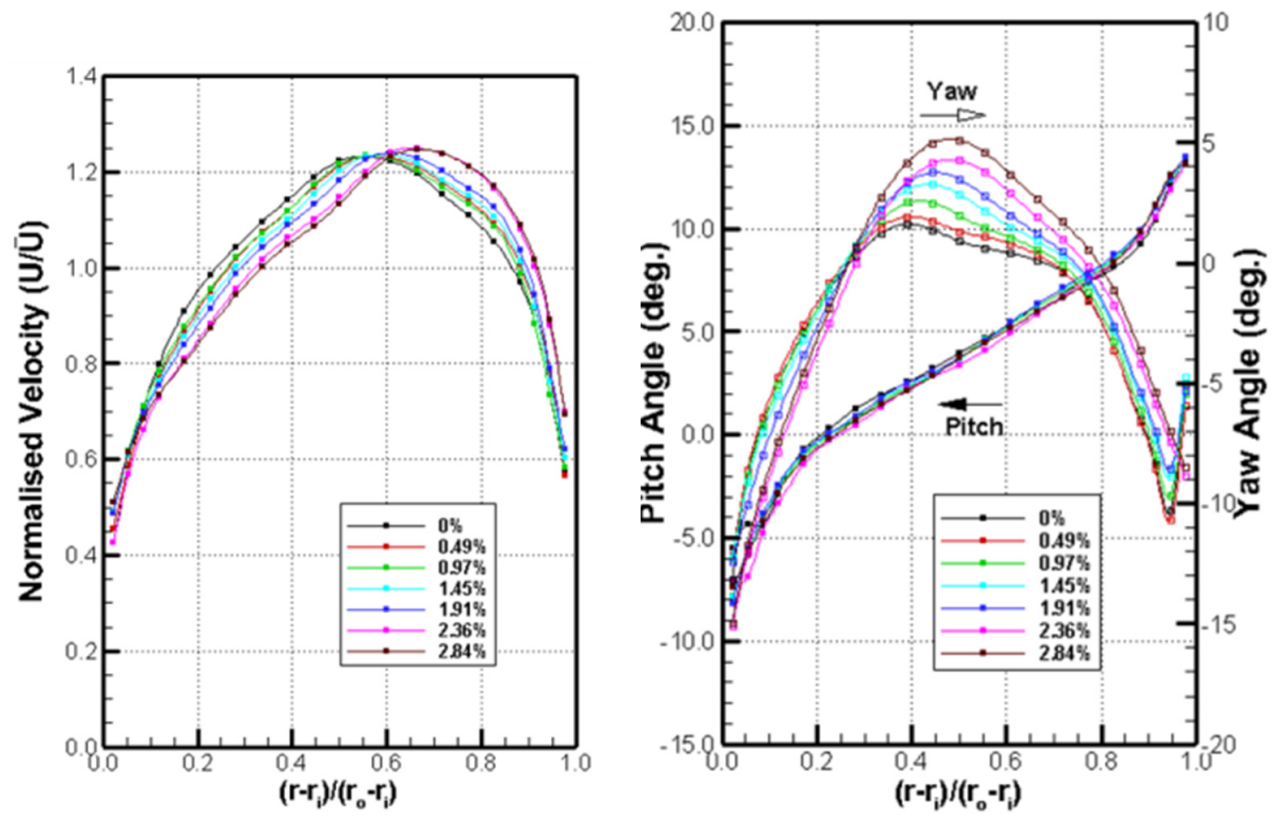

Fig. 21 Variation of total pressure loss with MFR

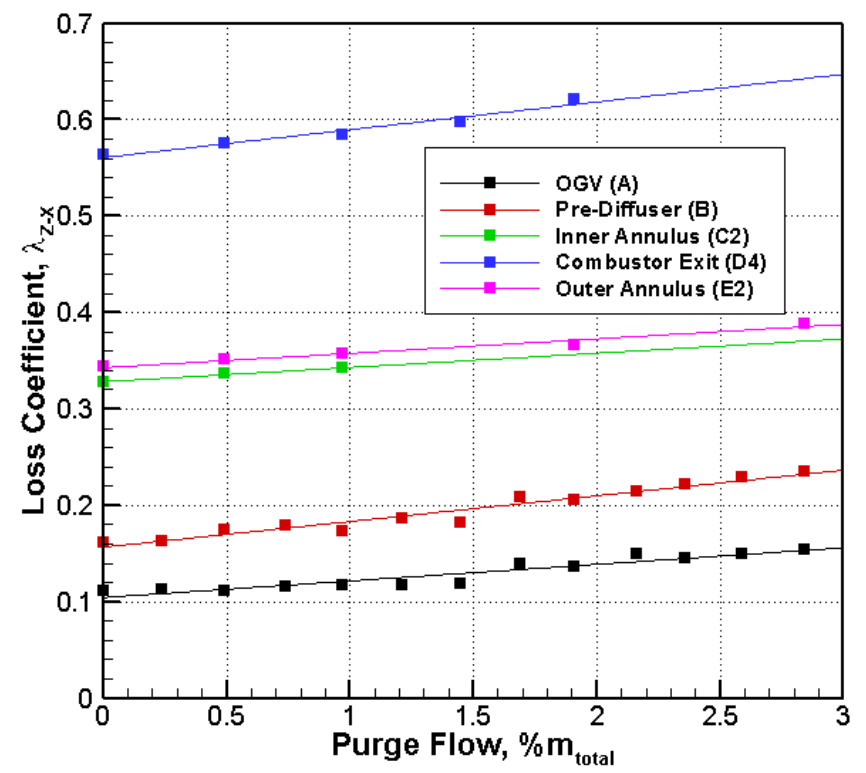


Fig. 22 Contours of axial velocity (CFD) at OGV exit for varying MFR and SF

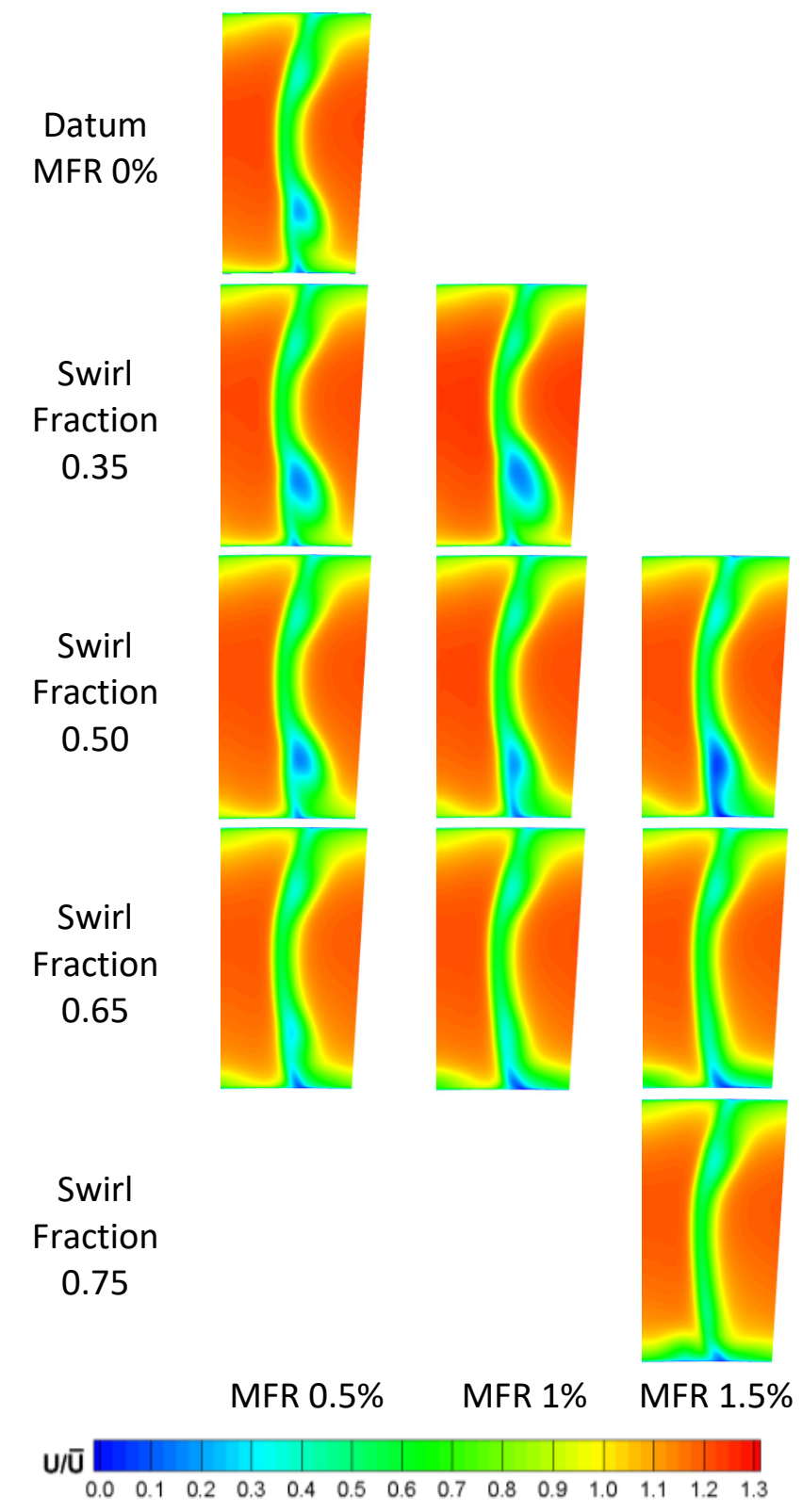


Fig. 23 Contours of axial velocity (CFD) at diffuser exit for varying MFR and SF

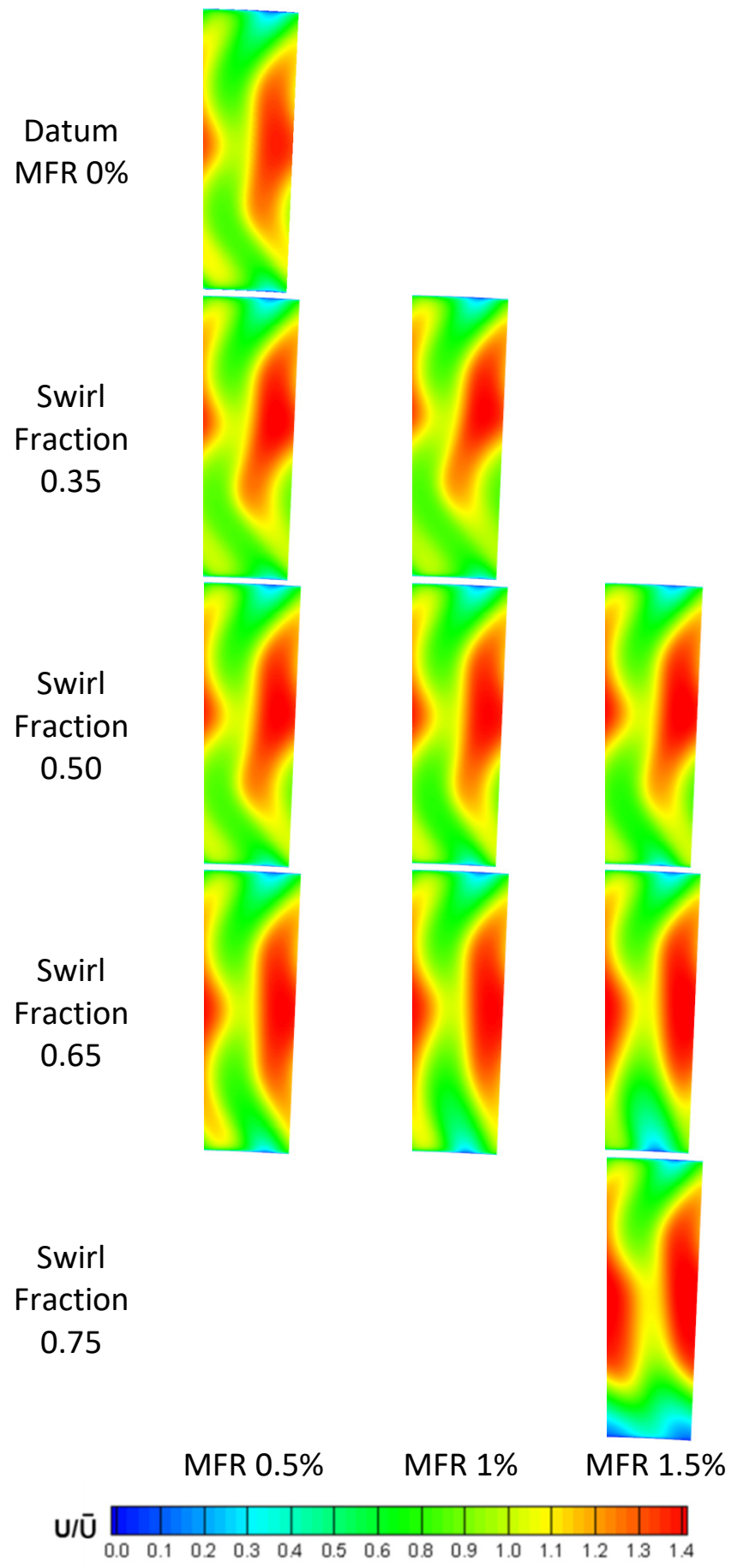


Fig. 24 Predicted velocity contours immediately upstream of the OGV

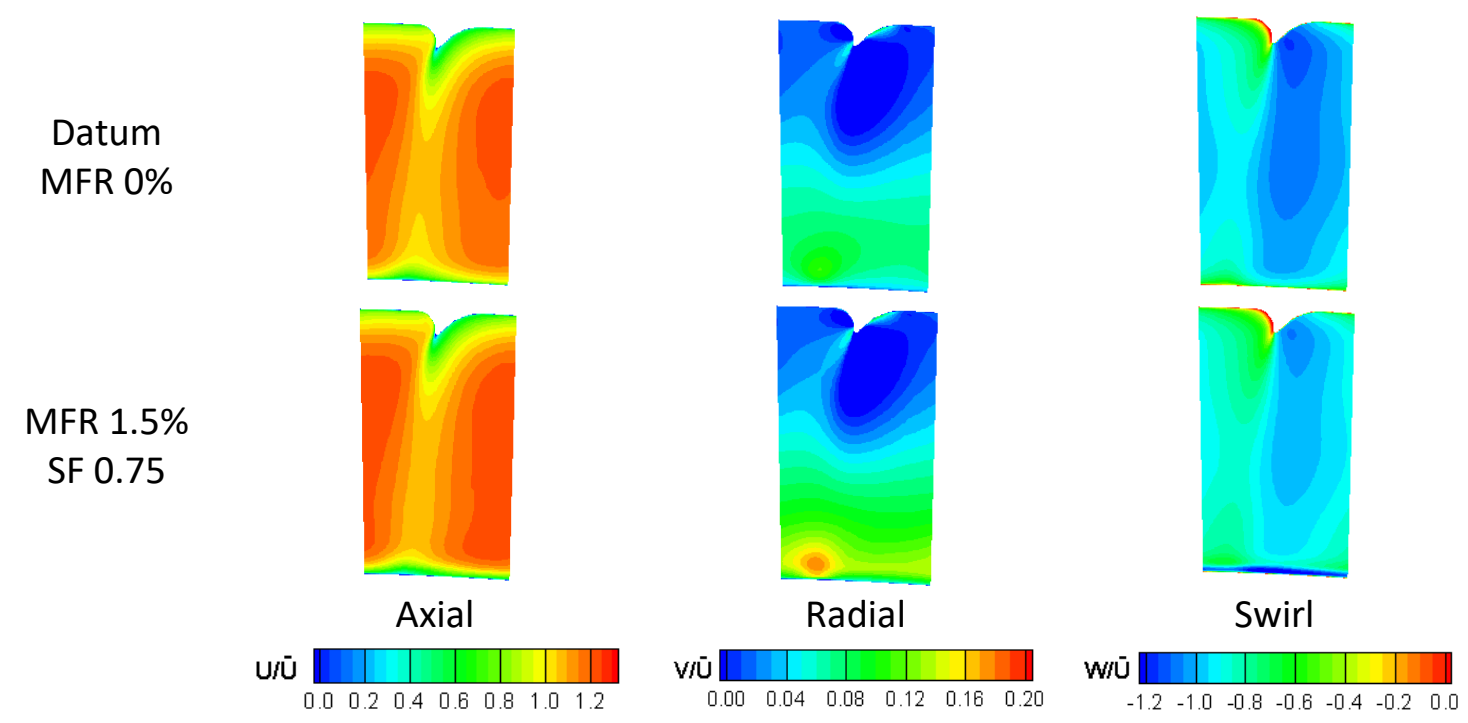

Fig. 25 Predicted streamlines close to the hub (MFR 1\%)
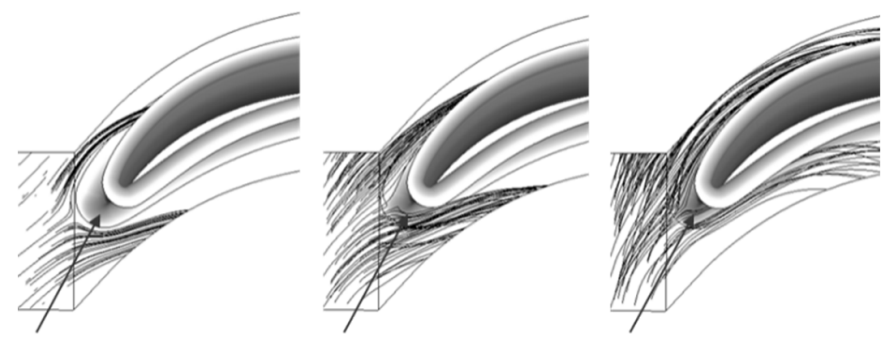
(a) Datum (SF 0)
(b) SF 0.35
(c) SF 0.5
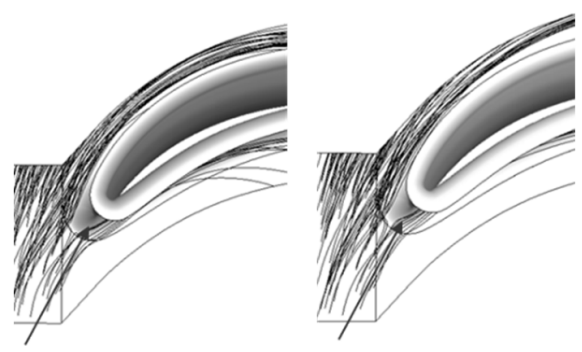

(d) SF 0.65

(e) SF 0.75 
Fig. 26 Predicted axial velocity contours on a plane at $25 \%$ height
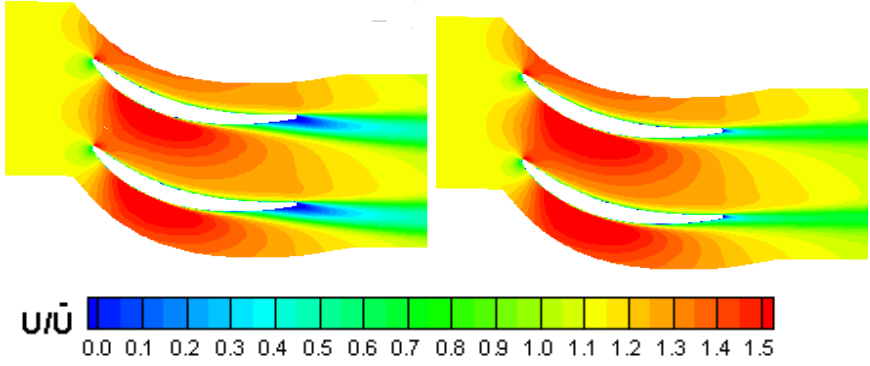
(a) Datum
(b) SF 0.75

Fig. 27 Streamlines released from the hub/purge (MFR 1\%)

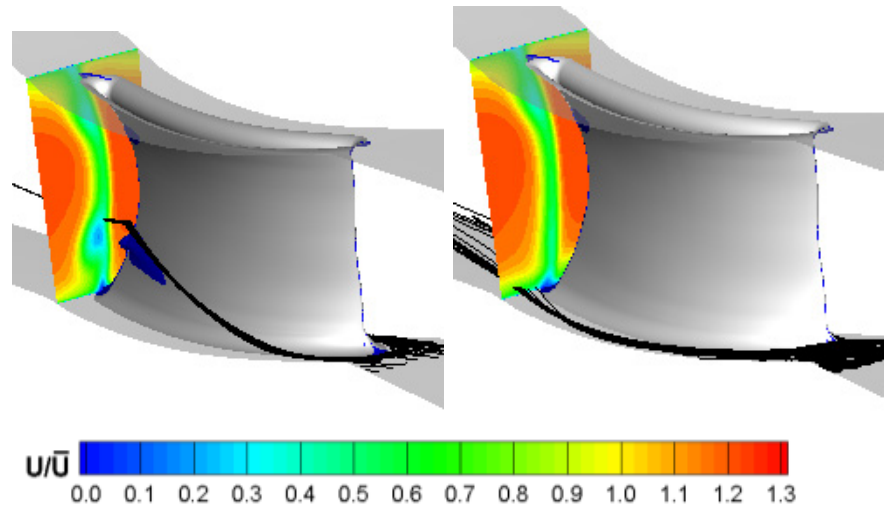
(a) Datum (0\%)
(b) SF 0.75

Fig. 28 Pre-swirl nozzle design

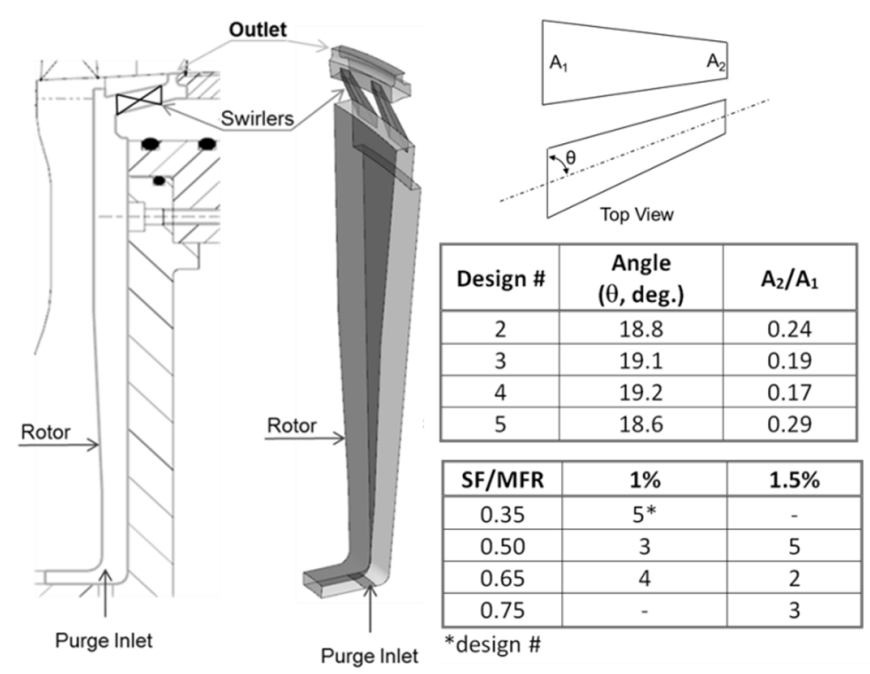


Fig. 29 Contours of axial velocity at OGV exit for varying MFR and SF

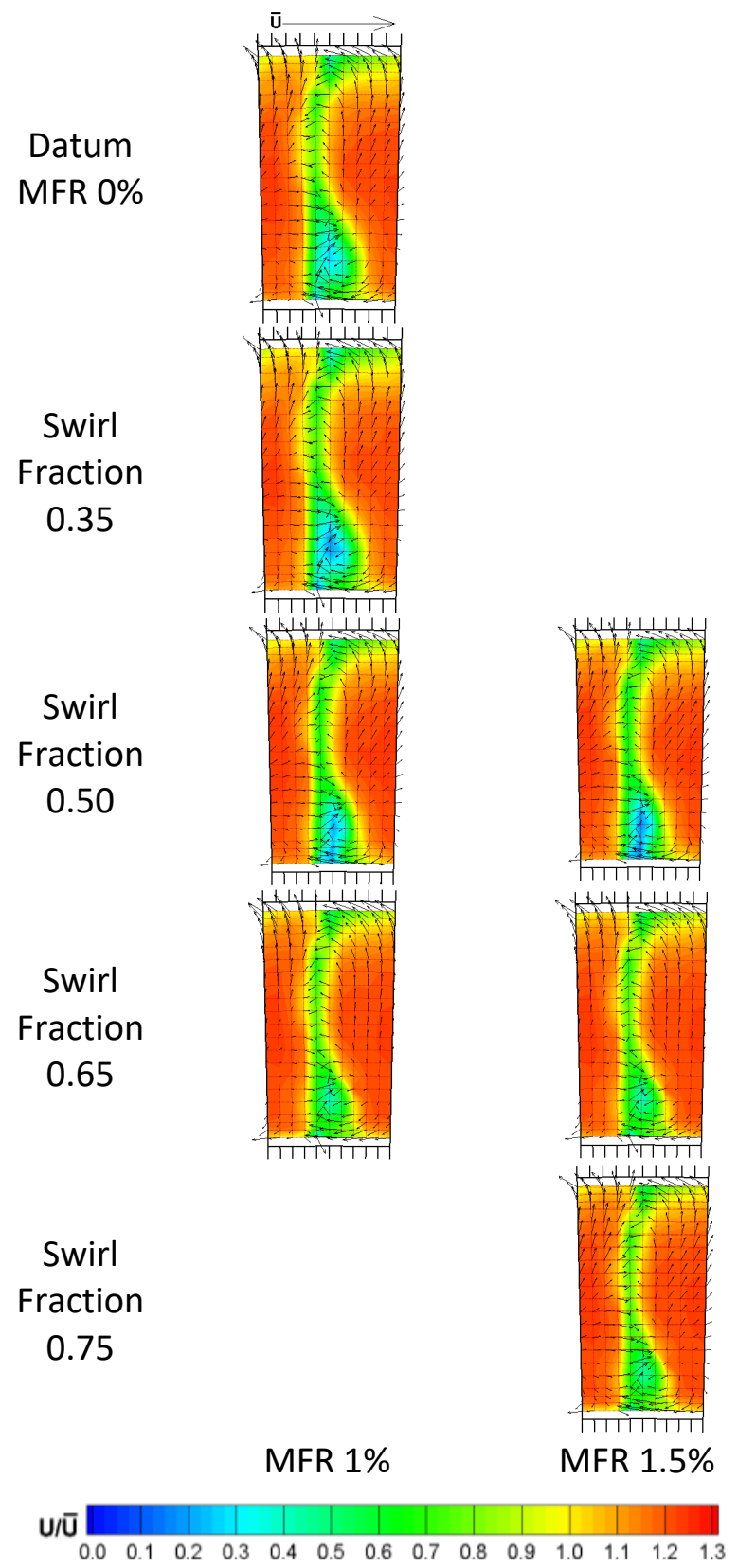


Fig. 30 Contours of axial velocity at pre-diffuser exit for varying MFR and SF

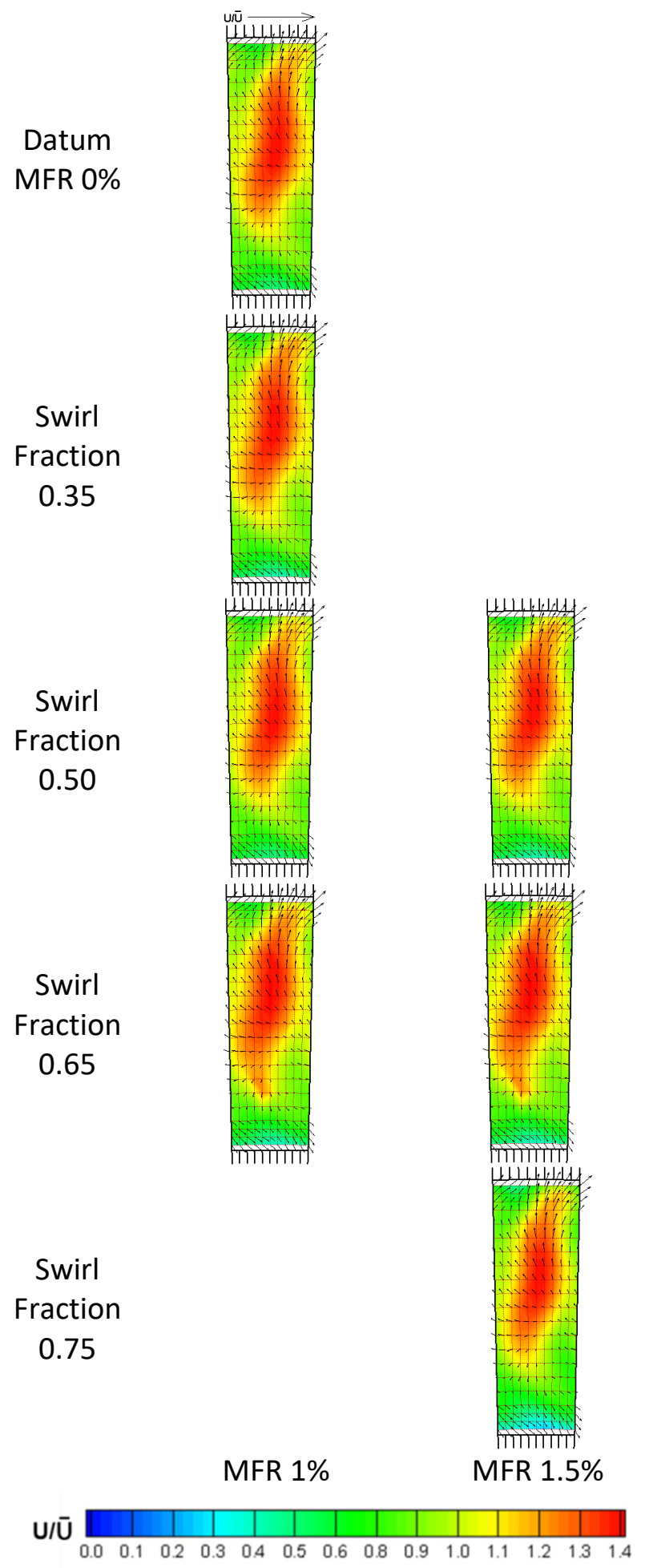


Fig. 31 Total pressure loss data, $\frac{\lambda_{Z-x}}{\lambda_{\text {datum }}}$

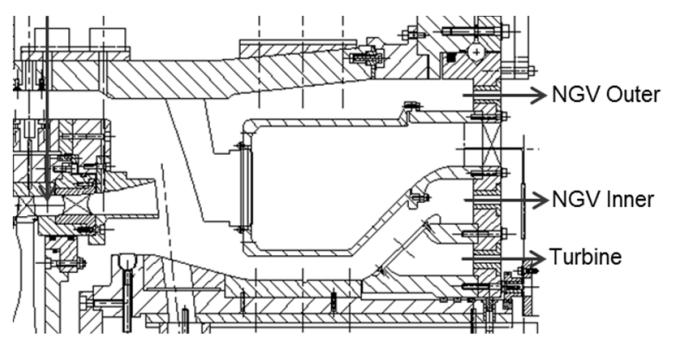

\begin{tabular}{|c|c|c|c|}
\hline SF & Turbine & $\begin{array}{c}\text { NGV } \\
\text { Inner }\end{array}$ & $\begin{array}{c}\text { NGV } \\
\text { Outer }\end{array}$ \\
\hline \hline $\mathbf{0 . 3 5}$ & 1.02 & 1.01 & 1.01 \\
\hline $\mathbf{0 . 5 0}$ & 0.91 & 0.94 & 0.98 \\
\hline $\mathbf{0 . 6 5}$ & 0.90 & 0.86 & 0.95 \\
\hline
\end{tabular}

(a) MFR $1 \%$

\begin{tabular}{|c||c|c|c|}
\hline SF & Turbine & $\begin{array}{c}\text { NGV } \\
\text { Inner }\end{array}$ & $\begin{array}{c}\text { NGV } \\
\text { Outer }\end{array}$ \\
\hline \hline $\mathbf{0 . 5 0}$ & 0.97 & 1.01 & 1.01 \\
\hline $\mathbf{0 . 6 5}$ & 0.95 & 0.97 & 0.96 \\
\hline $\mathbf{0 . 7 5}$ & 0.90 & 0.91 & 0.97 \\
\hline
\end{tabular}

(b) MFR 1.5\% 